\title{
Dead Sea evaporation by eddy covariance measurements vs. aerodynamic, energy budget, Priestley-Taylor, and Penman estimates
}

\author{
Jutta Metzger $^{1}$, Manuela Nied ${ }^{1}$, Ulrich Corsmeier ${ }^{1}$, Jörg Kleffmann ${ }^{2}$, and Christoph Kottmeier ${ }^{1}$ \\ ${ }^{1}$ Institute of Meteorology and Climate Research, Karlsruhe Institute of Technology (KIT), \\ P.O. Box 3640, 76021 Karlsruhe, Germany \\ ${ }^{2}$ Physikalische und Theoretische Chemie, Fakultät für Mathematik und Naturwissenschaften, \\ Bergische Universität Wuppertal, 42097 Wuppertal, Germany
}

Correspondence: Jutta Metzger (jutta.metzger@kit.edu)

Received: 30 March 2017 - Discussion started: 7 June 2017

Revised: 20 December 2017 - Accepted: 27 December 2017 - Published: 9 February 2018

\begin{abstract}
The Dead Sea is a terminal lake, located in an arid environment. Evaporation is the key component of the Dead Sea water budget and accounts for the main loss of water. So far, lake evaporation has been determined by indirect methods only and not measured directly. Consequently, the governing factors of evaporation are unknown. For the first time, long-term eddy covariance measurements were performed at the western Dead Sea shore for a period of 1 year by implementing a new concept for onshore lake evaporation measurements. To account for lake evaporation during offshore wind conditions, a robust and reliable multiple regression model was developed using the identified governing factors wind velocity and water vapour pressure deficit. An overall regression coefficient of 0.8 is achieved. The measurements show that the diurnal evaporation cycle is governed by three local wind systems: a lake breeze during daytime, strong downslope winds in the evening, and strong northerly along-valley flows during the night. After sunset, the strong winds cause half-hourly evaporation rates which are up to $100 \%$ higher than during daytime. The median daily evaporation is $4.3 \mathrm{mmd}^{-1}$ in July and $1.1 \mathrm{mmd}^{-1}$ in December. The annual evaporation of the water surface at the measurement location was $994 \pm 88 \mathrm{mma}^{-1}$ from March 2014 until March 2015. Furthermore, the performance of indirect evaporation approaches was tested and compared to the measurements. The aerodynamic approach is applicable for subdaily and multi-day calculations and attains correlation coefficients between 0.85 and 0.99 . For the application of the Bowen ratio energy budget method and the Priestley-Taylor
\end{abstract}

method, measurements of the heat storage term are inevitable on timescales up to 1 month. Otherwise strong seasonal biases occur. The Penman equation was adapted to calculate realistic evaporation, by using an empirically gained linear function for the heat storage term, achieving correlation coefficients between 0.92 and 0.97 . In summary, this study introduces a new approach to measure lake evaporation with a station located at the shoreline, which is also transferable to other lakes. It provides the first directly measured Dead Sea evaporation rates as well as applicable methods for evaporation calculation. The first one enables us to further close the Dead Sea water budget, and the latter one enables us to facilitate water management in the region.

\section{Introduction}

Since several years, the lake level of the Dead Sea declines by over $1 \mathrm{ma}^{-1}$ (approx. $600-700 \times 10^{6} \mathrm{~m}^{3} \mathrm{a}^{-1}$ ), meaning that the balance of the Dead Sea water budget is no longer sustained. The main water inflow to the Dead Sea is the Jordan River, but through anthropogenic interferences the discharge of the Jordan River into the Dead Sea decreased by $90 \%$ down to $60-400 \times 10^{6} \mathrm{~m}^{3} \mathrm{a}^{-1}$ (Asmar and Ergenzinger, 2002; Holtzman et al., 2005) compared to its natural discharge before 1955. Further natural inflow by groundwater discharge and surface runoff is in the range of $235-243 \times 10^{6} \mathrm{~m}^{3} \mathrm{a}^{-1}$ (Siebert et al., 2014). As the Dead Sea is a terminal lake, 
no natural outflow exists, but water is withdrawn from the lake for mineral and potash production. The loss of water is about $250 \times 10^{6} \mathrm{~m}^{3} \mathrm{a}^{-1}$ (Lensky et al., 2005). Thus, evaporation has to be the main loss of water from the Dead Sea. Even though evaporation is of particular importance for the Dead Sea water budget, the variation in evaporation estimates is high. The spread of the evaporation estimates ranges from 1.05 to $2.00 \mathrm{ma}^{-1}$, which is comparable to a volume loss of 700-1334 × $10^{6} \mathrm{~m}^{3} \mathrm{a}^{-1}$ (Stanhill, 1994; Salameh and ElNaser, 1999). It is important to reduce these uncertainties and assess the water budget components of the Dead Sea for a climatological purpose, but it is also of importance for the people in the area and the socio-economic development of the region to anticipate the evolution of these components and the resulting consequences for the environment. For instance, the lake level decline causes severe environmental problems. It influences the adjacent aquifers, their groundwater tables, and flow paths (Siebert et al., 2016), and it results in a shifting of the fresh-saline groundwater interface (Yechieli et al., 2006), which is connected to the development of sinkholes (Yechieli et al., 2006; Abelson et al., 2006). Since the 1980s, over 4000 sinkholes have formed at the western shore of the Dead Sea, which affect industrial, agricultural, and environmentally protected areas, leading to a substantial economic loss (Arkin and Gilat, 2000). Furthermore, evaporation influences the climatic conditions through a considerable change in the fraction of land and water surface. The changing fraction of water and land surfaces leads to a changing partitioning of the net radiation into sensible and latent heat flux. This results in a weaker horizontal gradient of the air temperature between the air masses over the water and land surface, resulting in a weaker pressure gradient, and thus weakens the lake breeze. As the lake breeze has an attenuating effect on the diurnal temperature amplitude and advects humidity towards the land, a weaker lake breeze results in higher maximum temperatures and decreasing humidity in the southern part of the valley (Alpert et al., 1997). Furthermore, it increases the diurnal penetration of the westerly winds into the valley in the afternoon. These westerly winds have often high wind velocities enhancing the evaporation and thus accelerating the lake level decline. Alpert et al. (1997) showed that in the 1940s, before the lake level and thus the water surface started to decrease, the much stronger easterly lake breeze delayed the penetration of the westerly winds considerably. The changing atmospheric conditions, together with the changing groundwater tables, result in a severe dieback of vegetation and the drying up of springs, endangering the unique flora and fauna in the Dead Sea region, such as the unique fish population of the Ein Feshkha reserve (Goren and Ortal, 1999; Lipchin et al., 2009).

In view of these environmental changes, resulting from the lake level decline, more accurate estimates of the Dead Sea evaporation are required (Kottmeier et al., 2016). Previous studies on the Dead Sea evaporation used indirect methods, such as water budget calculations (Salameh, 1996; Salameh and El-Naser, 2000); the energy budget approach (Stanhill, 1994; Lensky et al., 2005); aerodynamic methods (Salhotra et al., 1985; Oroud, 1994); or the combination of the latter two methods, called the combination approach (Calder and Neal, 1984; Asmar and Ergenzinger, 1999; Oroud, 2011). Variations in evaporation estimates between the studies result from assumptions on single water budget components such as groundwater inflow, different lengths of the time series of input variables, different measurement locations, and measurement uncertainties. To minimise the spread of 1.05 to $2.00 \mathrm{ma}^{-1}$ in the evaporation estimates (Stanhill, 1994; Salameh and El-Naser, 1999) and reduce uncertainties, direct measurements of the Dead Sea evaporation are required. The eddy covariance technique is the only method to obtain direct evaporation measurements. Thus, it is considered the most accurate and reliable method to estimate evaporation (Rimmer et al., 2009; Tanny et al., 2008). All other methods assess evaporation indirectly, which means that all measurement errors accumulate into the estimated evaporation (Assouline and Mahrer, 1993). With the high temporal resolution of the measurements, the data can also be linked to meteorological variables afterwards. However, it is quite expensive and difficult to perform such measurements as it requires highly accurate instruments and their continuous maintenance. Various studies using eddy covariance measurements have been conducted around the world and also in Israel. Assouline and Mahrer (1993) measured evaporation from Lake Kinneret, a freshwater lake north of the Dead Sea, crossed by the Jordan River, and Tanny et al. (2008) measured evaporation from a small reservoir also north of the Dead Sea using eddy covariance systems. However, to the authors' knowledge, no eddy covariance measurements were performed at the Dead Sea, where the environmental problems are severe. That is why, in the framework of the international DESERVE project (DEad SEa Research VEnue; Kottmeier et al., 2016), a new concept for assessing lake evaporation from onshore measurements was applied. Long-term eddy covariance measurements were conducted at the Dead Sea shore, which provided evaporation data of the water surface for onshore wind conditions. These measurements were combined with a statistical model to calculate evaporation for offshore wind conditions. The comprehensive data set is analysed in this paper with the following aims: to (i) provide an applicable method for measuring lake evaporation, using a station located at the shoreline; (ii) evaluate the actual evaporation rates of the Dead Sea at the measurement location and their diurnal and intra-annual variability; and (iii) evaluate the applicability of the commonly used indirect methods to calculate evaporation from the Dead Sea, and assess the capacity of the methods to retrieve the evaporation term, in the future, when eddy covariance measurements are not available any more. 
(a)
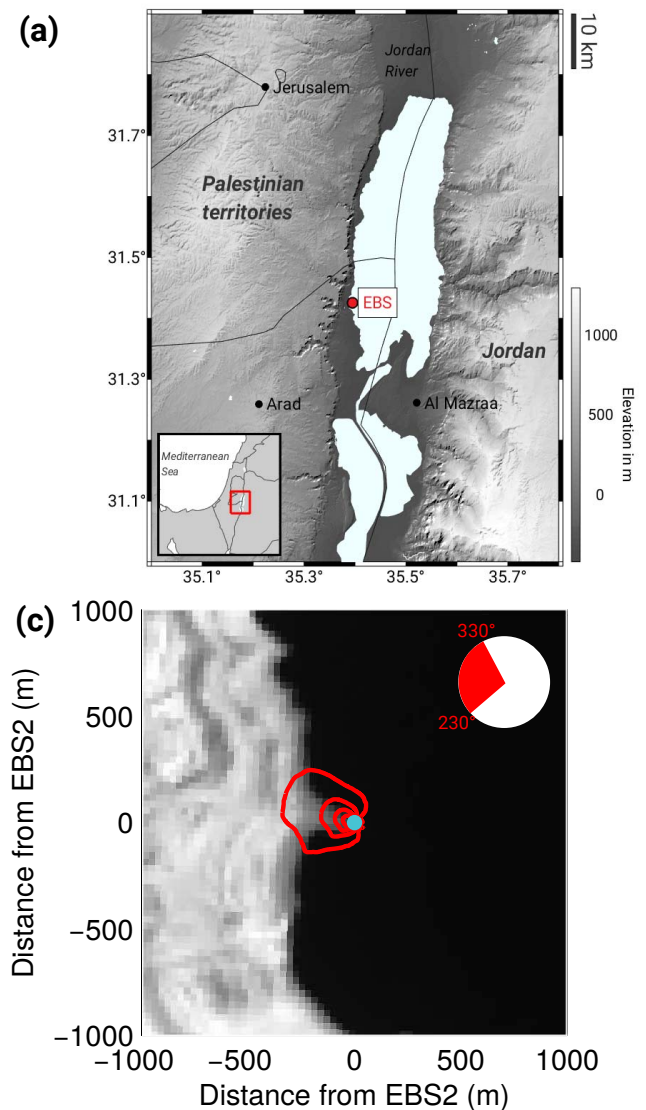

(b)

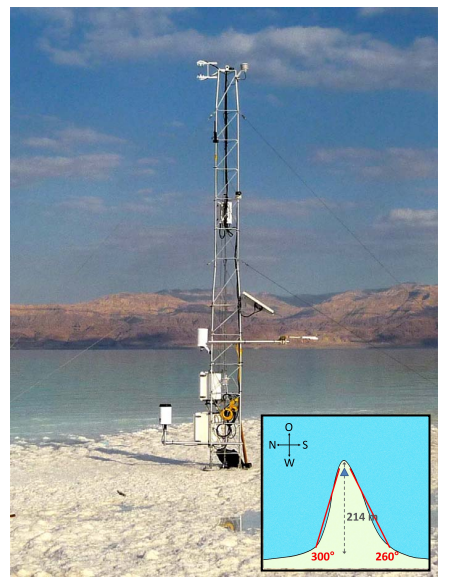

(d)

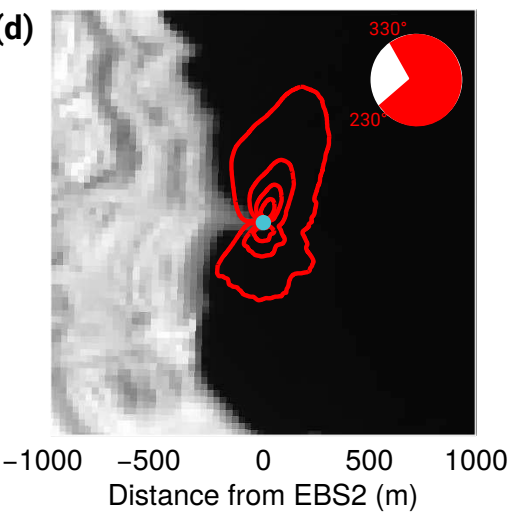

Figure 1. Map of the research area and location of the measurement site (a); image of the measurement site and sketch of the headland (inlet) (b); Landsat 8 images of the headland with location of the EBS (blue dot); and with the results of the footprint analysis (c, d). Contour lines (from inside to outside) represent 20,40,60, and $80 \%$ of the flux footprint area calculated with the footprint model of Kljun et al. (2015) for offshore wind conditions with wind direction between 230 and $330^{\circ}$ (c) and for the other wind directions (d). Satellite data were provided by the US Geological Survey.

\section{Measurement site and instrumentation}

The Dead Sea is a hypersaline terminal lake, located at the lowest point of the Jordan rift valley. It is surrounded by the Judean Mountains to the west and the Moab mountains to the east (Fig. 1a). Nowadays, the Dead Sea consists of two basins, the northern basin with approximately $600 \mathrm{~km}^{2}$ and the shallow artificial evaporation ponds in the south with approximately $280 \mathrm{~km}^{2}$, which are used for potash and mineral production. Since the 1950s, the lake level of the northern basin dropped by over $30 \mathrm{~m}$, from $-395 \mathrm{~m}$ a.m.s.l. to the current -429.9 ma.m.s.l. (Givati and Tal, 2016). The southern basin is held on a constant level by pumping water from the northern basin to the south. The area between the lake and the eastern and western mountain chains is rocky desert. When freshwater springs emerge along the shoreline, sufficient water is available for plants to grow. Although the total area of these vegetated areas is very small compared to the area covered by water or desert, these vegetated areas are very important for the diversity of the local ecosystems.
To measure the energy balance components of the water surface, an energy balance station (EBS) was installed directly at the shoreline (Fig. 1b). The station, was located $3 \mathrm{~km}$ south of Ein Gedi on the tip of a headland at the western shore of the Dead Sea (Fig. 1a). At the time of the measurements, the station was located at $-428 \mathrm{~m}$ a.m.s.l.; the headland was $214 \mathrm{~m}$ long and was surrounded by water from 300 to $260^{\circ}$ (insert in Fig. 1b).

At the station the following meteorological variables were measured and averaged over $10 \mathrm{~min}$ : temperature and humidity at $2 \mathrm{~m}$ height (HC2S3, Rotronic), temperature at $6 \mathrm{~m}$ (100KGA1A, BetaTherm), longwave and shortwave radiation components of the upper and lower half space (CNR4, Kipp\&Zonen) at $2 \mathrm{~m}$ height, precipitation (tipping bucket rain gauge 552202, Young), and atmospheric pressure (PTR330, Vaisala) at $1 \mathrm{~m}$ height. With a temporal resolution of $20 \mathrm{~Hz}$, water vapour, $\mathrm{CO}_{2}$ concentration, sonic temperature, and the three wind components were measured with an open path integrated gas analyser and sonic anemometer (IRGASON) from Campbell Scientific at $6 \mathrm{~m}$ height. 
As the station was located at the shoreline, the radiation measurements of the lower half space represented the land surface conditions. For the water surface they have to be calculated. The applied method is explained in Sect. 3.1. Furthermore, the heat storage of the lake was not measured and was therefore calculated as the residuum of the energy balance equation $\left(R_{\mathrm{n}}=\mathrm{LE}+H+\Delta Q\right)$ using half-hourly measurements. Notable hereby is that $\Delta Q$ also contains the possible non-closure of the energy balance. Considering the values of common energy balance closure studies (Foken, 2008; Wilson et al., 2002) the heat storage is thus most likely about $20 \%$ smaller than calculated.

\section{Data and methods}

Measurement data from March 2014 until March 2015 were analysed. To achieve the research aims, the following calculations and methods were applied. The shortwave and longwave radiation components of the lower half space were calculated. This is presented in Sect. 3.1. The latent and sensible heat flux were calculated from the $20 \mathrm{~Hz}$ data using the eddy covariance method. The principle of the method, the post-processing, and data quality control steps are presented in Sect. 3.2. Furthermore, a multiple regression model was used to calculate evaporation for offshore wind conditions and it was validated using the Monte Carlo cross validation (MCCV) technique, which is explained in Sect. 3.3. The indirect methods which are evaluated for calculating evaporation from the Dead Sea water surface and the performed sensitivity studies are presented in Sect. 3.4.

\subsection{Calculation of radiation components}

The measurements of the radiation components of the lower half space were not conducted directly over the water surface, but over the land surface. Therefore, these two components had to be calculated for the water surface. The reflected shortwave radiation was calculated using literature values of the Dead Sea albedo. Stanhill (1987) calculated the albedo of the Dead Sea surface from ship measurements and reported values of 0.06 in the summer months, 0.09 in the winter months, and an annual average of 0.07. He also reported albedo values from Kondrat'Ev (1969) for the latitude of the Dead Sea and the cloud cover observed in the northern part of the Dead Sea, which was 0.08 for November and 0.07 as an average annual albedo value. To confirm the validity of the literature values for our site, a short-term experiment was conducted in November 2014. The measured albedo values of 0.08 to 0.09 concur well with the literature values for winter. As the literature values for summer could not be compared to measurements, the annual average of 0.07 was used for all calculations. The longwave outgoing radiation was calculated using the Stefan-Boltzmann equation

$\mathrm{Rl} \uparrow=\epsilon \cdot k_{\mathrm{B}} \cdot T_{\mathrm{S}}^{4}$, with the water surface emissivity $\epsilon=0.98$ (e.g. Konda et al., 1994) and the Stefan-Boltzmann constant, $k_{\mathrm{B}}$. For the surface water temperature, $T_{\mathrm{S}}$, no in situ measurements were available. Also, remotely sensed surface water temperature products from satellites could not be used, as operational algorithms are calibrated to mean sea level and do not take the additional $421 \mathrm{~m}$ atmospheric layer in the Dead Sea valley into account. Nehorai et al. (2009) showed that a calibration of satellite data with in situ measurements is necessary. Furthermore, Nehorai et al. (2009) raised concerns that enhanced water vapour input into the atmosphere through evaporation causes stronger absorption of thermal IR radiation, leading to a screening of the Dead Sea surface and, thus, incorrect estimates of the surface water temperature. Based on the results of Nehorai et al. (2013), which showed that "surface water temperature is highly correlated to air temperature ( $\left.R^{2}=0.93-0.98\right)$ in all seasons", the Monin-Obukhov similarity approach was used to calculate surface water temperature from the measured air temperature (see Appendix A) and is further on referred to as $T_{\mathrm{MO}}$.

\subsection{Calculation of sensible and latent heat flux}

To calculate the sensible and latent heat flux from the wind, temperature, and humidity data measured by the IRGASON, the eddy covariance technique was used. This method uses the fluctuations of the vertical wind velocity and temperature around a temporal mean, here $30 \mathrm{~min}$, to calculate the sensible heat flux,

$H=c_{\mathrm{p}} \cdot \rho_{\mathrm{a}} \cdot \overline{w^{\prime} T_{\text {sonic }}^{\prime}}$,

and of the vertical wind velocity and the absolute humidity to calculate the latent heat flux:

$\mathrm{LE}=L_{\mathrm{v}} \cdot \overline{w^{\prime} a^{\prime}} \cdot 1000$.

The overbar represents the time average over $30 \mathrm{~min} ; c_{\mathrm{p}}$ is the specific heat at constant pressure in $\mathrm{J} \mathrm{K}^{-1} \mathrm{~kg}^{-1}, \rho_{\mathrm{a}}$ is the density of the air in $\mathrm{kg} \mathrm{m}^{-3}, w^{\prime}$ is the deviation of the vertical wind speed from the mean vertical wind speed in $\mathrm{m} \mathrm{s}^{-1}$, $T_{\text {sonic }}^{\prime}$ is the deviation of the sonic temperature from the mean sonic temperature in $\mathrm{K}$, and $a^{\prime}$ is the deviation of absolute humidity from the mean absolute humidity in $\mathrm{kg} \mathrm{m}^{-3} . L_{\mathrm{v}}$ is the latent heat of vaporisation in $\mathrm{kJ} \mathrm{kg}^{-1}$,

$L_{\mathrm{v}}=3148.4-2.37 \cdot T_{\mathrm{w}}$,

which depends on water temperature $T_{\mathrm{w}}$ in $\mathrm{K}$. For salt water, $L_{\mathrm{V}}$ increases with increasing salinity (Steiner, 1948). Therefore, for the calculation of the latent heat flux of the Dead Sea water, the salinity of the water has to be considered. To get the dependency of $L_{\mathrm{v}}$ on water temperature for the Dead Sea, respective measurements were undertaken. The vapour pressure of the Dead Sea water was measured as a function of water temperature with a calibrated capacitance manometer (see Appendix B). The following equation for the Dead 
Sea water was derived with the same units as in Eq. (4):

$$
L_{\mathrm{v}}=5150.6561-13.9530 \cdot T_{\mathrm{w}}+0.0162 \cdot T_{\mathrm{w}}^{2} .
$$

As evaporation takes place directly at the water surface of the lake, in a layer of approximately $10 \mu \mathrm{m}$ (Emery et al., 2001), surface water temperature should be used for the calculation of $L_{\mathrm{V}}$. Thus, the introduced $T_{\mathrm{MO}}$ was used for this purpose.

\subsubsection{Post-processing of eddy covariance data}

Post-processing of eddy covariance data is essential as field measurements generally do not fulfil all the theoretical concepts and assumptions of the eddy covariance theory. In particular, measurement limitations of the sensors, nonstationary conditions over the averaging period, and horizontal heterogeneity have to be considered (Foken et al., 2012). Therefore, the following post-processing steps were applied to the data set using the software package TK3 (Mauder and Foken, 2011). First, data were checked on plausibility using individual thresholds for each meteorological variable. Then, a spike detection, using the algorithm after Mauder et al. (2013), was applied. No fluxes were calculated if more than $10 \%$ of the data in the corresponding $30 \mathrm{~min}$ interval were missing. To account for a not perfectly levelled sonic anemometer, meaning that the vertical axis is not perpendicular to the surface and thus the vertical wind measurements are affected by the horizontal wind components, the coordinate system of the sonic anemometer was rotated using the planar fit method after Wilczak et al. (2001). It rotates the coordinate system to the main wind direction and then rotates the system around the $y$ axis, such that the $z$ axis is positioned perpendicular to the horizontal plan and that the mean vertical wind over the period that is used to define the plane is $0 \mathrm{~ms}^{-1}$.

Spectral corrections were performed to account for the loss of energy for high frequencies, due to path-length averaging and limited sensor frequency response, following the approach after Mauder and Foken (2011). The influence of humidity on sonic temperature plays an important role for the calculation of the sensible heat flux. To account for this influence, the Schotanus correction (Schotanus et al., 1983) was applied. This correction is particularly important for flux calculations at sites with high humidity fluctuations, such as over the water surface. The water vapour measurements are influenced by temperature and humidity changes, as only the molar density of water vapour is measured and not the mass mixing ratio. To consider the density fluctuations, corrections after Webb et al. (1980) were applied.

\subsubsection{Quality control and data coverage}

The overall performance of the system was very good, and only $2.1 \%$ of the sensible heat flux data and $2.4 \%$ of the latent heat flux data were missing. To assure data quality of the flux measurements, several quality criteria were applied. La- tent heat flux data were rejected when the signal strength of the radiation source to measure the water vapour was below $50 \%$, when the variability of the signal from one $10 \mathrm{~min}$ average to the next one was higher than $0.6 \%$ within the $30 \mathrm{~min}$ time interval, and during precipitation events, as a disturbance of the water vapour measurements was expected for these conditions. Due to these quality criteria $10 \%$ of the latent heat flux data were rejected. Further quality control was performed using the steady state test after Foken and Wichura (1996), which analyses each 30 min time interval on stationarity and the integral turbulence characteristics (ITC) test after Foken et al. (2012), which checks data on fully developed turbulent conditions. A combined quality flag considering the steady state test and the ITC test (Foken, 1999) was used to classify the data into nine classes. Class 1 to 6 describe data, which can be used for the analysis, and classes 7 to 9 were rejected. After the quality control, data availability was $86.3 \%$ for sensible and $78.5 \%$ for latent heat flux data. Furthermore, the flux footprint had to be considered. A footprint analysis was performed, using the model after Kljun et al. (2015). Results show that flux data for wind directions between 230 and $330^{\circ}$ had to be rejected as the fetch was over land, while the aim of this station was to measure evaporation from the water surface (Fig. 1c). For northerly to southerly wind directions, the fetch was over water and the average fetch contributing to $80 \%$ of the flux ranged from 0 to $300 \mathrm{~m}$ and 0 to $600 \mathrm{~m}$, respectively. (Fig. 1d). The amount of flux data rejected due to the footprint was about $19 \%$. The total available flux data from the water surface was thus $67.1 \%$ for sensible and $59.2 \%$ for latent heat flux. This was reasonably good compared to other eddy covariance studies at other lakes, where a data availability between 36 and $56 \%$ was reported (e.g. Jonsson et al., 2008; Mammarella et al., 2015; Bouin et al., 2012).

\subsection{Multiple regression model for the latent heat flux}

Through the installation of the EBS at the shoreline, flux data from the water surface are only available for onshore wind conditions, and all data for offshore wind conditions, i.e. wind directions between 230 and $330^{\circ}$, are rejected for the analysis (Fig. 1c). However, for the analysis of the diurnal and intra-annual variability of the evaporation rates, estimates of the fluxes for these wind directions are important, as otherwise evaporation rates in the afternoon, when westerly downslope winds prevail, would be missing. Therefore, a multiple regression model is applied to find a suitable relationship between the turbulent fluxes and governing meteorological variables, such as wind speed, vapour pressure deficit, net radiation, and surface water temperature. The vapour pressure deficit is calculated using the surface water temperature $T_{\mathrm{MO}}$ (see Appendix C). A Monte Carlo cross validation, first introduced by Picard and Cook (1984), is performed to test the model's robustness and get an estimate of the model error. The work flow is as follows: (i) data be- 
Table 1. Selection of commonly used equations to calculate evaporation (Ev) in $\mathrm{mm} \mathrm{d}^{-1}$. The original version and the default version (V0) used in Sect. 3.4 and 4.4 are presented.

\begin{tabular}{|c|c|c|c|}
\hline Method & Name & Original equation & Default version (V0) \\
\hline Aerodynamic/mass transfer & Aerodynamic & ${ }^{\mathrm{a}} \mathrm{Ev}=\frac{0.622}{\rho_{\mathrm{w}} p} C_{e} \rho_{\mathrm{a}} v_{\mathrm{a}}\left(E_{\mathrm{w}}-e_{\mathrm{a}}\right)$ & $C_{e}=\frac{\kappa^{2}}{\left(\ln \left(\frac{z \mathrm{~m}-z_{d}}{z_{0}}\right)\right)^{2}}$ \\
\hline Energy budget & BREB & ${ }^{\mathrm{b}^{\mathrm{Ev}}}=\frac{R_{\mathrm{n}}-G-F_{\mathrm{n}}-\Delta Q}{\rho_{\mathrm{w}} \cdot L_{\mathrm{v}} \cdot(1+\mathrm{Bo})}$ & $F / G, \Delta Q$ \\
\hline Combination & Priestley-Taylor & ${ }^{\mathrm{c}} \mathrm{Ev}=c_{\mathrm{PT}} \frac{\Delta \cdot\left(R_{\mathrm{n}}-G\right)}{\rho_{\mathrm{w}} L_{\mathrm{v}}(\Delta+\gamma)}$ & 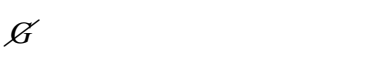 \\
\hline \multirow[t]{2}{*}{ Combination } & Penman & $\mathrm{d}_{\mathrm{Ev}}=\frac{\Delta \cdot R_{\mathrm{n}}+\gamma C_{e} v_{\mathrm{a}} \rho_{\mathrm{w}} L_{\mathrm{v}}\left(E_{\mathrm{a}}-e_{\mathrm{a}}\right)}{\rho_{\mathrm{w}} L_{\mathrm{v}}(\Delta+\gamma)}$ & orig. Eq. used \\
\hline & Bowen ratio & $\mathrm{Bo}=\frac{H}{\mathrm{LE}} \approx \frac{c_{\mathrm{p}} \cdot p}{0.622 \cdot L_{\mathrm{v}}} \cdot \frac{T_{\mathrm{S}}-T_{\mathrm{a}}}{E_{\mathrm{w}}-e_{\mathrm{a}}}=\gamma$ & $\frac{T_{\mathrm{S}}-T_{\mathrm{a}}}{E_{\mathrm{w}}-e_{\mathrm{a}}}$ \\
\hline \multicolumn{2}{|c|}{$C_{e}=$ transfer coefficient for evaporation } & \multicolumn{2}{|l|}{$R_{\mathrm{n}}=$ net radiation } \\
\hline \multicolumn{2}{|c|}{$c_{\mathrm{p}}=$ specific heat capacity at constant pressure } & \multicolumn{2}{|l|}{$T_{\mathrm{S}}=$ surface water temperature } \\
\hline \multicolumn{2}{|c|}{$c_{\mathrm{PT}}=1.26=$ Priestley-Taylor coefficient } & \multicolumn{2}{|l|}{$T_{\mathrm{a}}=$ air temperature } \\
\hline \multicolumn{2}{|c|}{$e_{\mathrm{a}}=$ vapour pressure at air temperature } & \multicolumn{2}{|l|}{$v_{\mathrm{a}}=$ wind velocity } \\
\hline \multicolumn{2}{|c|}{$E_{\mathrm{a}}=$ saturation vapour pressure at air temperature } & \multicolumn{2}{|l|}{$\mathrm{Bo}=$ Bowen ratio } \\
\hline \multicolumn{2}{|c|}{$E_{\mathrm{W}}=$ saturation vapour pressure at surface water temperature } & \multicolumn{2}{|l|}{$\gamma=$ psychometric constant } \\
\hline \multicolumn{2}{|l|}{$\mathrm{Ev}=$ evaporation } & \multicolumn{2}{|c|}{$\Delta=$ slope of the saturation vapour pressure vs. temperature curve } \\
\hline \multicolumn{2}{|l|}{$F_{\mathrm{n}}=$ net advected heat flux } & \multicolumn{2}{|c|}{$\Delta Q=$ heat storage of the lake } \\
\hline \multicolumn{2}{|l|}{$G=$ ground heat flux } & \multicolumn{2}{|l|}{$\rho_{\mathrm{a}}=$ air density } \\
\hline \multicolumn{2}{|c|}{$L_{\mathrm{V}}=$ latent heat of vaporisation } & \multicolumn{2}{|l|}{$\rho_{\mathrm{w}}=$ water density } \\
\hline
\end{tabular}

a Brutsaert (1982), ${ }^{\mathrm{b}}$ Dingman (2002), ${ }^{\mathrm{c}}$ Priestley (1972), ${ }^{\mathrm{d}}$ Van Bavel (1966)

tween 230 and $330^{\circ}$ are removed from the data set. (ii) Two approaches are used to divide the data in a training and validation data set. The first approach uses randomly chosen data points of about $15 \%$ of the total data set as validation data and the second approach uses a randomly chosen wind sector of $45^{\circ}$ as validation data. The usage of these two approaches allows the general test of the model's robustness but also its sensitivity on a certain wind sector. (iii) After each division a regression model is built with the training data set and then applied on the data of the validation group. The deviation of the calculated from the measured flux values yields the model error of one realisation. (iv) After multiple applications, in this case 500 times, the model error is averaged and results in the prediction error of the regression model. A large prediction error indicates a dependency of the model on the choice of the training data set and therefore has to be rejected.

\subsection{Indirect methods to estimate evaporation}

For the calculation of evaporation, several equations, based on different physical approaches, exist. Each approach connects evaporation to different meteorological parameters and is designed for different time intervals, ranging from subdaily calculations to a time interval of at least 7 days. Four commonly used indirect methods to estimate evaporation (Table 1) will be tested in this paper by comparing their results to the eddy covariance measurements. An aerodynamic approach also known as mass transfer approach, the energy budget method, and two combination approaches, namely the Priestley-Taylor and Penman equation, will be evaluated on time intervals of $1,7,14$, and 28 days. The aerodynamic approach is the only approach which is also designed for sub-daily time intervals and will thus also be tested for 30 min time intervals. Additionally, sensitivity studies are performed to quantify the influence of simplification within the approaches, which are often made in literature.

The first method is the aerodynamic approach after Brutsaert (1982), where only wind speed and vapour pressure deficit are required. With the assumption of equal transfer coefficients for evaporation and momentum $\left(C_{e}=C_{d}\right)$ under neutral conditions, the logarithmic wind profile can be used (Van Bavel, 1966) (Table 1, V0). This is the default version of the aerodynamic method for the sensitivity studies. The second method is the energy budget method expressed as the Bowen ratio energy budget (BREB) (Table 1). For this approach several of the input variables are difficult to obtain. The amount of net advected heat into the water body, $F_{\mathrm{n}}$, meaning the heat advected into the lake by water inflow and precipitation, and the loss of heat by water outflow have to be known. If the in- and outflows are small compared to the size of the water body, or water temperatures are similar, the term can be neglected (Dingman, 2002; Rosenberry et al., 2007). Moreover, the ground heat flux $G$, meaning the heat exchange at the bottom of the lake, is required. It can usually 
Table 2. Overview of the sensitivity studies performed for the evaporation equations. Sensitivity studies applied to a method are marked with an $\mathrm{X}$.

\begin{tabular}{|c|c|c|c|c|c|}
\hline Version & Explanation & Aerodynamic & BREB & Priestley-Taylor & Penman \\
\hline 0 & Default (see Table 1) & $\mathrm{X}$ & $\mathrm{X}$ & $\mathrm{X}$ & $\mathrm{X}$ \\
\hline 1 & Atmospheric Stability & $\mathrm{X}$ & - & - & $\mathrm{X}$ \\
\hline 2 & Heat storage term derived with hysteresis approach & - & $\mathrm{X}$ & $\mathrm{X}$ & $\mathrm{X}$ \\
\hline 3 & Heat storage term derived as a linear function of $R_{\mathrm{n}}$ from V0 & - & $\mathrm{X}$ & $\mathrm{X}$ & $\mathrm{X}$ \\
\hline 4 & Removal of $T_{\mathrm{MO}}$ from $R_{\mathrm{n}}$ calculation & - & - & - & $X$ \\
\hline 5 & $\begin{array}{l}\text { Removal of } T_{\mathrm{MO}} \text { from } R_{\mathrm{n}} \text { calculation and heat storage term } \\
\text { from hysteresis approach }\end{array}$ & - & - & - & $X$ \\
\hline 6 & $\begin{array}{l}\text { Removal of } T_{\mathrm{MO}} \text { from } R_{\mathrm{n}} \text { calculation and heat storage term } \\
\text { derived as a linear function of } R_{\mathrm{n}} \text { from } \mathrm{V} 4\end{array}$ & - & - & - & $X$ \\
\hline
\end{tabular}

be neglected, as the amount for deep lakes is small compared to the other components (Henderson-Sellers, 1986). Another component difficult to obtain is the heat storage of the lake, $\Delta Q$. It requires measurements of lake temperature at different depths from a raft station or a ship. On longer timescales it can often be neglected. Because of the aforementioned reasons and the difficulty in obtaining these three terms, the net advected heat, the ground heat flux, and the heat storage term are neglected in many studies. Thus, for the default version (V0) of the BREB method these three terms are neglected (Table 1). Even though neglecting the heat storage on the timescales investigated is a coarse assumption, it serves as a basis for the sensitivity studies V1 and V2. Using V0, only net radiation, surface water temperature, air temperature, and the vapour pressure deficit have to be known, which are relatively easy to obtain and thus an easy approach to calculate evaporation. The third method to calculate evaporation is the combination approach, considering the energy budget and the aerodynamic influence. Priestley (1972) proposed an equation which considers the aerodynamic influence by using an empirically gained coefficient of $c_{\mathrm{PT}}=1.26$ (Table 1). Because of the same reason as mentioned above, the ground heat flux is neglected in the default version (V0) of the Priestley-Taylor equation. Method four is a combination of the energy budget equation with the aerodynamic approach first developed by Penman (1948). In his approach he already neglected net advected heat, the ground heat flux, and the heat storage. Van Bavel (1966) further generalised Penman's equation by replacing the empirical wind function through the logarithmic wind profile, assuming neutral conditions (Table 1). This equation will be used as the default version (V0) for testing the Penman approach.

In total, six sensitivity studies were performed. An overview of the sensitivity studies and to which of the methods they are applied to is given in Table 2 . Sensitivity study V1 considers non-neutral atmospheric conditions, by incorporating stability correction factors into $C_{e}$. As only the aerodynamic and the Penman approach are based on masstransfer, V1 is applied to these two equations only. Studies $\mathrm{V} 2$ and V3 consider the heat storage of the lake $\Delta Q$ and are applied to the BREB, Priestley-Taylor, and Penman method. For this purpose $R_{\mathrm{n}}$ is replaced with $\left(R_{\mathrm{n}}-\Delta Q\right)$. Duan and Bastiaanssen (2015) proposed a hysteresis approach to calculate the heat storage term, depending only on the net radiation $\left(\Delta Q=a+b \cdot R_{\mathrm{n}}+c \cdot \mathrm{d} R_{\mathrm{n}} / \mathrm{d} t\right)$. This approach is applied to the measurement data and the resulting coefficients $(a, b, c)$ are used in sensitivity version $\mathrm{V} 2$ to calculate $\Delta Q$. To avoid the use of the calculated heat storage from the measurements, in V3 it is assumed that the heat storage term is directly proportional to the net radiation and that the deviation of the default version (V0) from the measurements equals the heat storage term. The last three sensitivity tests were applied to the Penman approach only. In V4 the uncertainty caused by the calculated longwave outgoing radiation with $T_{\mathrm{MO}}$ was eliminated by using an approximation from Kohler and Parmele (1967) where they calculated the longwave net radiation and the psychrometric constant using air temperature only. This further reduces the amount of necessary input parameters, which makes the equation more easily applicable, when net radiation of the water surface is not directly measured. In version V5 the approximation after Kohler and Parmele (1967) is applied together with the hysteresis model for the heat storage term (V2). The last sensitivity test (V6) combines the approximation after Kohler and Parmele (1967) with a linear function for the heat storage term, derived from the deviation of V4 from the measurements.

\section{Results}

\subsection{Meteorological conditions}

In the Dead Sea valley the measured average annual air temperature was $26.5^{\circ} \mathrm{C}$ for the measurement period, which was slightly higher than the long-term annual mean of $25.9^{\circ} \mathrm{C}$ found by Hecht and Gertman (2003) for the period 1992 to 2002. Maximum daily air temperatures regularly exceeded $40^{\circ} \mathrm{C}$ in summer (Fig. 2) and the annual precipitation was $273 \mathrm{~mm}$. (Fig. 2). The precipitation amount for the observation period is high compared to the mean annual precipitation of the standard normal period 1961 to 1990 of $80 \mathrm{~mm}$ 


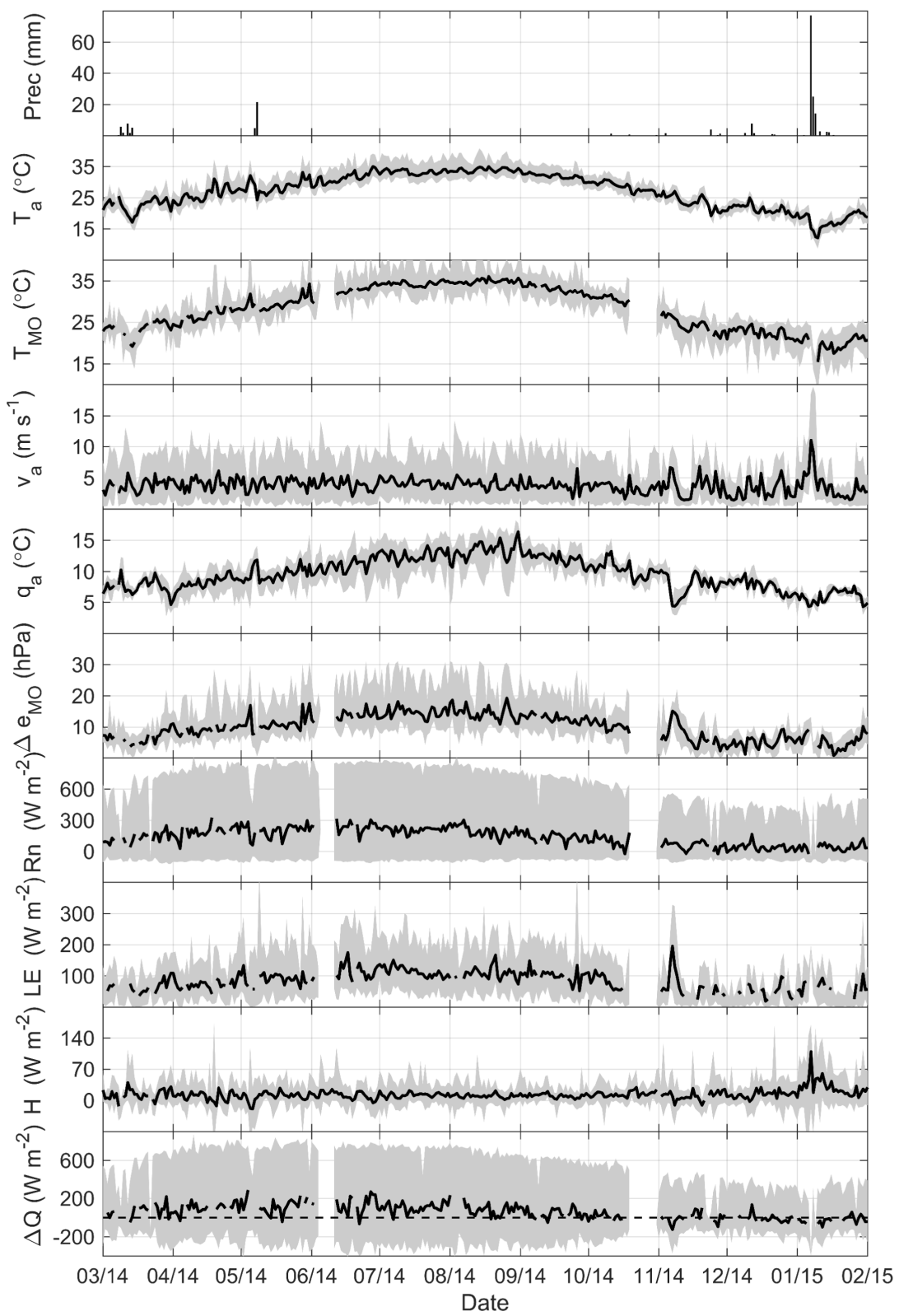

Figure 2. Daily precipitation (prec), $24 \mathrm{~h}$ running mean of air temperature $\left(T_{\mathrm{a}}\right)$, surface water temperature $\left(T_{\mathrm{MO}}\right)$, wind velocity $\left(v_{\mathrm{a}}\right)$, specific humidity $\left(q_{\mathrm{a}}\right)$, vapour pressure deficit $\left(\Delta e_{\mathrm{MO}}\right)$, net radiation $\left(R_{\mathrm{n}}\right)$, latent heat flux (LE), sensible heat flux $(H)$, and heat storage $(\Delta Q)$. The grey shaded area represents the range between daily minimum and maximum values of the respective variable.

(Goldreich, 2003). It resulted from a few heavy precipitation events in January 2015, which made the observation period 2014-2015 a relatively wet year for the area. The wind velocity did not show a clear annual cycle. From March until October, mean, maximum, and minimum were relatively similar. However, during winter, a different behaviour was found when the wind increased in connection with the stronger large-scale activity (Fig. 2). The relative uniform wind velocities from spring until autumn resulted from periodic local wind systems, governing the conditions in the valley. Between sunrise and sunset a lake breeze prevailed, leading to north-easterly winds at the station with a median wind velocity of $3 \mathrm{~m} \mathrm{~s}^{-1}$ (Figs. 2 and 3a). The lake breeze occurred throughout the year, with an occurrence rate exceeding $70 \%$ of the days in summer 2014, and 58 and $48 \%$ of the days in spring and autumn 2014, respectively. In winter, the synoptic conditions gained more influence and often superimposed the local wind field such that a north-easterly lake breeze was only observed on about $32 \%$ of the days and a southeasterly flow on $26 \%$ of the days in winter 2014-2015. In the evening, north-westerly downslope winds, often enhanced by the Mediterranean Sea breeze (Alpert et al., 1997; Naor 
Spring 2014
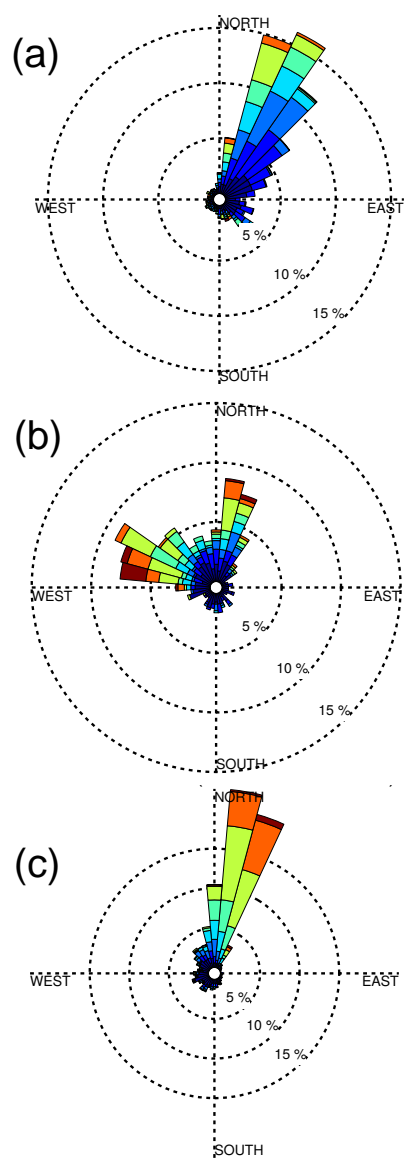

Summer 2014
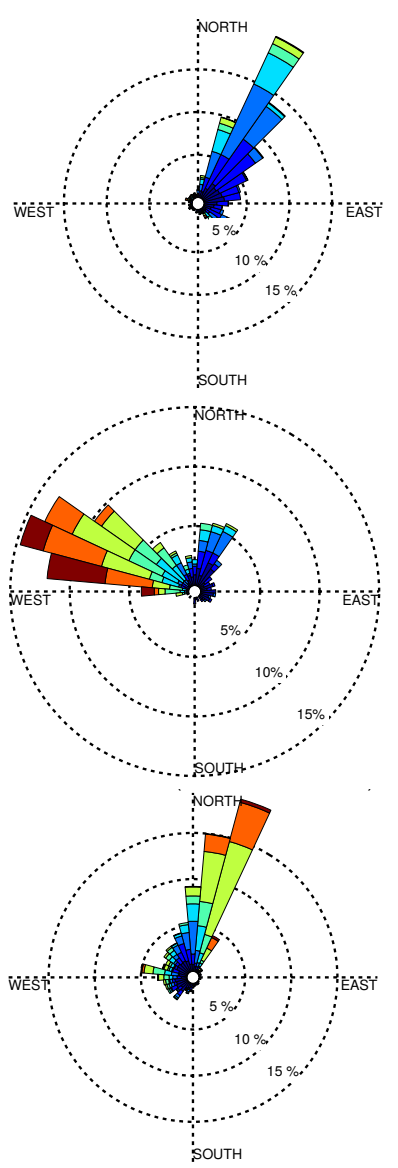

Autumn 2014
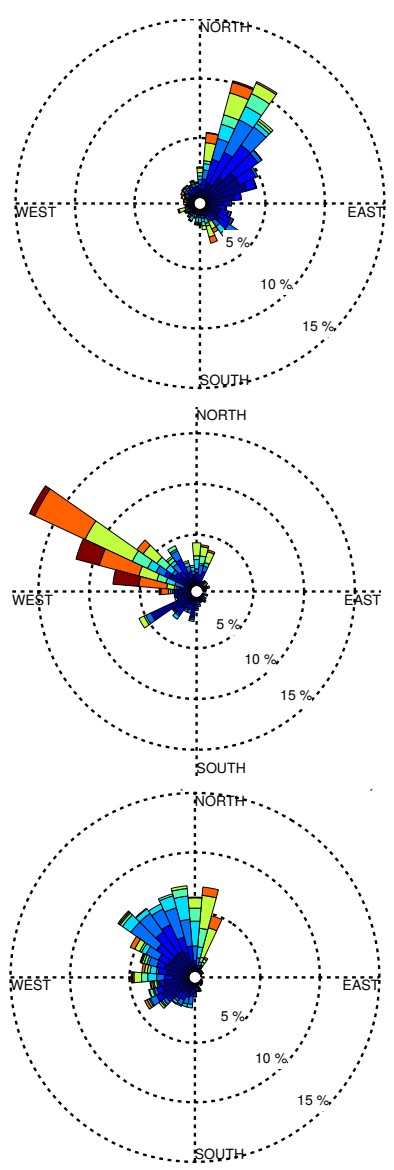

Winter 2014/15
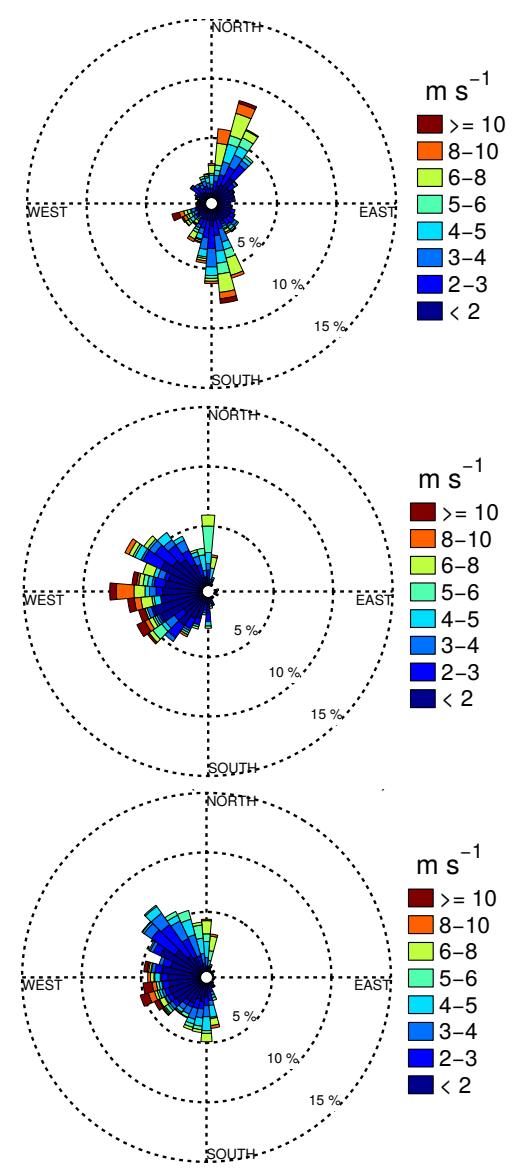

Figure 3. Wind conditions between (a) 06:30 and 17:30 LT, (b) 17:30 and 20:30 LT, and (c) 20:30 and 06:30 LT. Data are shown for spring, summer, autumn, and winter 2014-2015.

et al., 2017), lead to accelerated wind velocities in the valley (Fig. 3b). These downslope winds occurred on about $57 \%$ of the days in summer and still $28 \%$ of the days in spring and $45 \%$ of the days in autumn. The downslope winds regularly reached mean wind velocities exceeding $10 \mathrm{~m} \mathrm{~s}^{-1}$ (Fig. 3b). During the night, a northerly along-valley flow prevailed mainly in spring and summer. The along-valley flow also reached wind velocities exceeding $10 \mathrm{~m} \mathrm{~s}^{-1}$ (Fig. 3c). The difference between the saturation vapour pressure at the water surface and the actual vapour pressure of the air $(\Delta e)$ had a mean value of $9.75 \mathrm{hPa}$. It had a clear annual cycle with maximum values above $30 \mathrm{hPa}$ in summer. Individual peaks in winter were related to special synoptic conditions, e.g. in the beginning of November, when a Red Sea Trough with a central axis advected dry and warm air into the valley over the course of several days. The annual cycles of the energy balance components are also shown in Fig. 2. The net radiation reaches maximum values exceeding $900 \mathrm{~W} \mathrm{~m}^{-2}$ in summer and about $500 \mathrm{~W} \mathrm{~m}^{-2}$ in winter. The sensible heat flux is small throughout the year. The mean latent heat flux values are higher in summer compared to the winter months.
However, on individual days in winter some latent heat flux values even exceeded the summer values. The heat storage shown in Fig. 2 shows that a considerable amount of energy is stored but also released over the course of the day. However, this term also contains the possible non-closure of the energy balance. Assuming common literature values of the non-closure (Wilson et al., 2002; Foken, 2008), the actual heat storage is most likely $20 \%$ smaller than shown here. On a seasonal basis the sensible heat flux accounts for about 5 to $10 \%$ of the net radiation in spring, summer, and autumn, whereas it accounts for nearly $40 \%$ in winter. The latent heat flux accounts for 43 and $53 \%$ of the net radiation in spring and summer, leading to a high heat storage amount of 51 and $42 \%$, respectively. In autumn over $74 \%$ of the net radiation is transformed into latent heat flux, such that the heat storage amount is small. In winter, the latent heat flux is in the range of $92 \%$ of the net radiation, meaning that the heat storage term is negative, releasing the heat to the atmosphere, represented through the higher sensible heat flux. Similar behaviour of the flux components was found for other lakes (e.g. Giadrossich et al., 2015). 
Table 3. Correlation coefficients for latent heat flux (LE) with wind speed $\left(v_{\mathrm{a}}\right)$, net radiation $\left(R_{\mathrm{n}}\right)$, surface water temperature $\left(T_{\mathrm{MO}}\right)$, and vapour pressure deficit calculated with surface water temperature $\left(\Delta e_{\mathrm{MO}}\right)$. Correlation coefficients over 0.5 are bold. Data are shown for the meteorological seasons 2014-2015 and the entire data set.

\begin{tabular}{lrrrr}
\hline & $v_{\mathrm{a}}$ & $R_{\mathrm{n}}$ & $T_{\mathrm{MO}}$ & $\Delta e_{T_{\mathrm{MO}}}$ \\
\hline Spring & $\mathbf{0 . 6 8}$ & -0.19 & 0.07 & 0.06 \\
Summer & $\mathbf{0 . 7 3}$ & -0.16 & 0.00 & -0.12 \\
Autumn & $\mathbf{0 . 5 3}$ & 0.16 & 0.36 & 0.46 \\
Winter & $\mathbf{0 . 8 1}$ & 0.27 & 0.19 & $\mathbf{0 . 5 6}$ \\
Total & $\mathbf{0 . 5 9}$ & 0.03 & 0.42 & 0.38 \\
\hline
\end{tabular}

\subsection{Multiple regression model for the latent heat flux}

The footprint model showed that the fetch of the fluxes is over land for wind directions between 230 and $330^{\circ}$. The affected amount of latent heat flux data is $19 \%$. Through the predominant local wind systems, these wind directions occur almost exclusively in the evening between 17:30 and 20:30 LT (LT = UTC + 2) from spring until autumn (Fig. 3) and, thus, most of the data within this time frame are excluded. For the analysis of the diurnal variability of the latent heat flux from the water surface, and also for the intraannual and annual amounts, it is important to close these gaps. A multiple regression model was applied to calculate the latent heat flux for offshore wind conditions. The choice of the input variables for the multiple regression model was based on the analysis of the linear correlation between the latent heat flux and different meteorological variables. The correlation coefficients for the variables are shown in Table 3. For the latent heat flux, the highest correlation is achieved with wind speed, with correlation coefficients between 0.53 and 0.81 for the different seasons, followed by the vapour pressure deficit, and finally surface water temperature and net radiation. This is different from cooler climates where the highest correlation was found with vapour pressure deficit (Blanken et al., 2000; Nordbo et al., 2011) and also from lakes in Mediterranean climate, where vapour pressure deficit had the same impact as wind speed (e.g. Bouin et al., 2012). The influence of the vapour pressure deficit varies strongly between the different seasons. In spring and summer no correlation exists between latent heat flux and the vapour pressure deficit, but in autumn, winter, and for the total data set correlation coefficients are between 0.38 and 0.56. Although correlation with individual meteorological variables is already good, none of the variables can fully explain the latent heat flux. A stepwise multiple regression model was applied with the following variables to find the best fitting solution for the latent heat flux:

$X_{\mathrm{LE}}=\left(v_{\mathrm{a}}, \Delta e_{T_{\mathrm{MO}}}, R_{\mathrm{n}}, T_{\mathrm{MO}}\right)$.

The model $X_{\mathrm{LE}}$ gave the same dependency for all seasons. The latent heat flux depended on a linear combination of
Table 4. Results of the stepwise linear regression model $X_{\mathrm{LE}}$ for the latent heat flux. The corresponding correlation coefficient $(R)$ of the model after a variable is added to the model is shown. For the model with $v_{\mathrm{a}} \cdot \Delta e_{\mathrm{MO}}$, the correlation coefficient $(R)$ is given. The prediction errors yielded by the MCCV with randomly chosen validation data points $\left(\mathrm{er}_{\mathrm{r}}\right.$ ) and randomly chosen validation sectors $\left(\mathrm{er}_{\mathrm{s}}\right)$ are shown for both models. Results are shown for the meteorological seasons and for the entire data set.

\begin{tabular}{lrrrrrrrr}
\hline & \multicolumn{9}{c}{$X_{\mathrm{LE}}$} & & \multicolumn{3}{c}{$v_{\mathrm{a}} \cdot \Delta e_{T_{\mathrm{MO}}}$} \\
\cline { 2 - 4 } \cline { 8 - 10 } & $v_{\mathrm{a}}$ & $\Delta e_{T_{\mathrm{MO}}}$ & $\mathrm{er}_{\mathrm{r}}(\%)$ & $\mathrm{er}_{\mathrm{S}}(\%)$ & & $R$ & $\mathrm{er}_{\mathrm{r}}(\%)$ & $\mathrm{er}_{\mathrm{s}}(\%)$ \\
\hline Spring & 0.68 & 0.77 & 0.32 & 8.61 & & 0.79 & -0.01 & 10.57 \\
Summer & 0.73 & 0.77 & 0.17 & 2.31 & & 0.76 & -0.17 & 1.60 \\
Autumn & 0.53 & 0.82 & -0.16 & 1.25 & & 0.84 & 0.42 & 6.17 \\
Winter & 0.81 & 0.85 & 2.94 & 0.02 & & 0.85 & 4.72 & -0.31 \\
Total & 0.59 & 0.80 & 0.96 & 4.79 & & 0.83 & 0.80 & 6.78 \\
\hline
\end{tabular}

Table 5. Coefficients of the model equations to calculate latent heat flux (LE). The equations have the general form: $\mathrm{LE}=a+b \cdot v_{\mathrm{a}}+$ $c \cdot \Delta e$. Coefficients are shown for the meteorological seasons 20142015 and the entire data set.

\begin{tabular}{rrrrrr}
\hline & Spring & Summer & Autumn & Winter & Total \\
\hline$a$ & -32.52 & -25.41 & -58.91 & -15.29 & -36.92 \\
$b$ & 13.33 & 18.41 & 16.21 & 11.07 & 14.31 \\
$c$ & 5.51 & 4.61 & 7.56 & 4.46 & 6.13 \\
\hline
\end{tabular}

wind speed and vapour pressure deficit. The correlation coefficient ranged from 0.77 in spring and summer to 0.85 in winter (Table 4). The aerodynamic approach to estimate evaporation is based on the product of wind speed and vapour pressure deficit (Table 1), instead of a linear combination. For comparison, the correlation of the product of wind speed and vapour pressure deficit with the latent heat flux was calculated additionally and resulted in nearly the same correlation coefficients (Table 4). The results of the Monte Carlo cross validation analysis reveal that the model $X_{\mathrm{LE}}$ results in small prediction errors. The prediction error varies between -0.16 and $2.94 \%$ for randomly chosen data points and for randomly chosen control sectors between 0.02 and $8.61 \%$. The model with $v_{\mathrm{a}} \cdot \Delta e_{T_{\mathrm{MO}}}$ results in higher model errors varying between -0.17 and $4.72 \%$ for randomly chosen data points and between -0.31 and $10.57 \%$ for randomly chosen control sectors. Even though the correlation coefficients are similar for both models, model $X_{\mathrm{LE}}$ was chosen for the calculation of the latent heat flux, instead of the commonly used $\Delta e \cdot v_{\mathrm{a}}$, because of the robustness and the smaller prediction error. The model coefficients are shown in Table 5.

In summary, the regression model $X_{\mathrm{LE}}$ provides a suitable and robust method to calculate the latent heat flux for offshore wind conditions. To ensure that the model is not applied outside the conditions for which it has been constructed, the extreme values of offshore wind velocity and vapour pressure deficit are not considered to calculate evaporation and it is checked that data are always within the model 

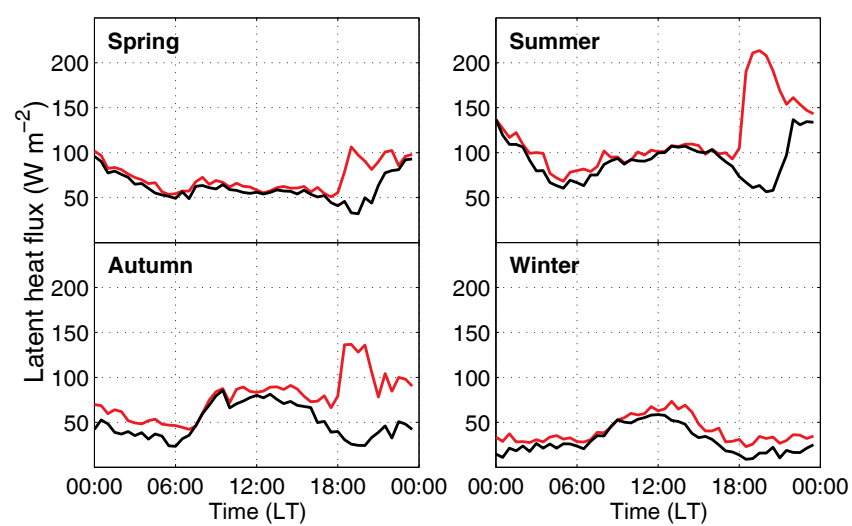

Corrected flux $\longrightarrow$ Measured flux

Figure 4. Median diurnal cycles of the measured latent heat flux (black lines) and the latent heat flux corrected with the multiple regression model for wind directions between 230 and $330^{\circ}$ (red lines).

boundaries. Evaporation values, which can not be calculated because wind velocity or vapour pressure deficit are outside the boundaries are treated as missing values. With this method $90 \%$ of the originally rejected latent heat flux data due the fetch criteria can be calculated with the model. The total data availability is increased from 59.2 to $76.8 \%$.

The calculation of the latent heat flux for offshore wind conditions is especially important for the analysis of the diurnal cycle of the latent heat flux, and also for its intraannual variation. The comparison of the mean diurnal cycles of the measured fluxes with the cycles including the calculated values for offshore wind conditions (corrected fluxes) shows that during the day the differences are small (Fig. 4). As the prevailing wind direction is north-east, caused by the lake breeze, nearly no calculations are necessary, as the flux footprint is located over water (Fig. 1d). However, in the evening, when downslope winds prevail in spring, summer, and autumn, the differences are quite large (Fig. 4). During this time period, the measured values represent the latent heat flux from the land surface, with values around or below $50 \mathrm{~W} \mathrm{~m}^{-2}$. In contrast, the calculated values represent the latent heat flux from the water surface, with values up to $200 \mathrm{~W} \mathrm{~m}^{-2}$ in summer. Hence, the regression model allows a detailed analysis of the diurnal cycle of the fluxes, even though the station is located at the shoreline.

\subsection{Diurnal and intra-annual variability}

The latent heat flux is the dominating turbulent flux at the water surface (Fig. 2). It has a strong diurnal cycle. During daytime, the latent heat flux reaches values of $100 \mathrm{~W} \mathrm{~m}^{-2}$ in summer and autumn, and $70 \mathrm{~W} \mathrm{~m}^{-2}$ in spring and winter (Fig. 4). The maximum values are reached after sunset around 19:00 LT in spring, summer, and autumn. In spring

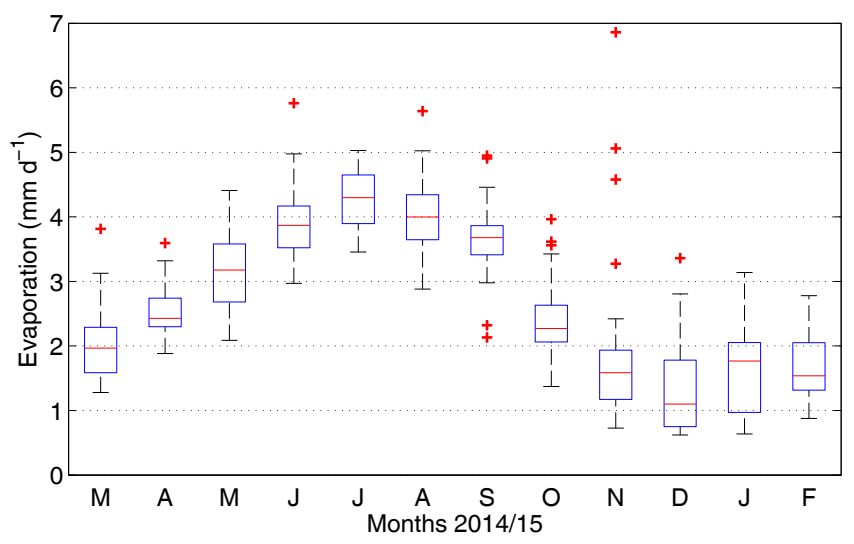

Figure 5. Box plot of daily evaporation rates. Red lines indicate medians, the edges of the boxes are the 25th and 75th percentiles, the whiskers extend to the most extreme data points not considered outliers, and outliers are plotted individually by red crosses.

about $105 \mathrm{~W} \mathrm{~m}^{-2}$ are reached, in summer $213 \mathrm{~W} \mathrm{~m}^{-2}$, and in autumn $136 \mathrm{~W} \mathrm{~m}^{-2}$. During the night, the latent heat flux continues to be higher than during daytime and reaches minimum values shortly before sunrise. In winter, this late maximum is not observable and values during nighttime are lower than during daytime. The unusual diurnal cycle with highest latent heat flux values after sunset and during the night are clearly connected to the diurnal cycle of wind speed and vapour pressure deficit and thus to the wind systems. This is most pronounced in summer. During the day, the lake breeze with relatively low wind velocities, (Fig. 3a) causes moderate latent heat flux rates. The downslope winds in the evening have generally high wind velocities (Fig. 3b) and advect drier air into the valley, which results in high vapour pressure deficits and thus high latent heat flux values. The high values during night result from accelerated wind velocities (Fig. 3c), rather than high vapour pressure deficits.

For the calculation of daily and yearly evaporation, stillexisting data gaps were closed, using the median evaporation rate of the corresponding time step of the respective month. The uncertainty due to this gap-filling method was estimated using the median absolute deviation, which is the median of the absolute deviations from the data's median.

In spring, evaporation rates steadily increase until a maximum median evaporation of $4.3 \mathrm{~mm} \mathrm{~d}^{-1}$ is reached in July (Fig. 5). Afterwards, evaporation rates decrease until a minimum median evaporation of $1.1 \mathrm{~mm} \mathrm{~d}^{-1}$ is reached in December (Fig. 5). The annual cycle of evaporation follows the solar cycle with a time lag of about 1 month. Summing the evaporation values over the whole measurement period results in an annual evaporation of $994.5 \pm 88.2 \mathrm{~mm}$, where $81.2 \mathrm{~mm}$ of the uncertainty result from the gap-filling method and $7.0 \mathrm{~mm}$ from to the regression model. Also visible in Fig. 5 is the higher variation of the daily evaporation rates between November and February. This is the so-called wet 
season when synoptic patterns gain more influence on the atmospheric conditions in the valley (Bitan, 1974, 1976). The governing factors of evaporation, i.e. wind speed and vapour pressure deficit, are very variable during this time. On the one hand, winter storms with rain and high air humidity can reach the region, which decreases the evaporation rate. On the other hand, winter storms without rain but high wind velocities, which advect very dry air to the Dead Sea, can significantly increase the evaporation rate (Shafir and Alpert, 2011). The highest variability (not considering outliers) can be seen in January, with daily evaporation rates between 0.6 and $3.1 \mathrm{~mm} \mathrm{~d}^{-1}$. In November, daily evaporation rates vary between 0.7 and $2.4 \mathrm{mmd}^{-1}$, but on 3 consecutive days evaporation rates exceed these values. Evaporation rates of 5.1, 6.9, and $4.6 \mathrm{~mm} \mathrm{~d}^{-1}$ are measured, which is the absolute maximum of the whole measurement period. These extreme evaporation rates are caused by a Red Sea Trough with a central axis and a dominant high to the east, which causes south-easterly winds above the valley. It can be observed that through the complex orography a pressuredriven channelling occurs along the valley axis, resulting in a near-surface northerly wind with constantly high averaged wind speed exceeding $10 \mathrm{~m} \mathrm{~s}^{-1}$ (not shown). This leads to the advection of warm and very dry air over the lake, which, together with the high wind velocities, increases the evaporation dramatically. This case was also used to test the performance of the regression model as on these 3 consecutive days only 3 out of 72 evaporation values had to be calculated due to the fetch criteria. Applying the regression model to calculate evaporation on these 3 days completely yields good results for day 1 and three were the difference was only $4-5 \%$, but it also shows the potential underestimation of extreme evaporation rates as the model underestimated the daily evaporation on the second day by $18 \%$.

\subsection{Indirect methods to estimate evaporation}

With the comprehensive data set of the measurements, it is possible, for the first time, to evaluate four of the commonly used evaporation equations for their applicability for Dead Sea evaporation on different timescales (30 min, 1, 7, 14 and $28 \mathrm{~d}$ ) and perform a sensitivity analysis on simplifications and assumption used for the equations. The main goal is the identification of the best fitting equation, by using measurements purely made on land, as data from raft stations or buoys are often difficult to obtain (Giadrossich et al., 2015). The calculated evaporation rates are compared to the eddy covariance measurements and evaluated in terms of their correlation coefficient, slope and offset of the regression line, mean difference, and monthly differences between the estimates and the measurements. Additionally, the relative overor underestimation of the annual evaporation is compared to the measured amount of $994 \pm 88.2 \mathrm{~mm}$.

The first equation is the aerodynamic approach after Brutsaert (1982) (Table 1). This equation uses wind speed and vapour pressure deficit as governing factors. In the default version (V0) the stability of the atmosphere is not considered. The aerodynamic approach is the only approach designed for sub-daily time intervals. The correlation coefficient for 30 min averages is 0.85 and it tends to overestimate evaporation rates. The slope of the regression line is 1.26 (Table 6) and the mean difference is $0.92 \pm 0.54 \mathrm{~mm} \mathrm{~d}^{-1}$. For time intervals of $1 \mathrm{~d}$ and longer, the aerodynamic approach yields better results. The correlation coefficients vary between 0.94 for $1 \mathrm{~d}$ intervals and 0.99 for $28 \mathrm{~d}$ intervals, mean differences are smaller, $0.02 \pm 0.54 \mathrm{~mm} \mathrm{~d}^{-1}$ for the $1 \mathrm{~d}$ interval, and the slopes of the regression lines vary around 1.10 (Table 6, Fig. 6a,V0). The mean differences are evenly distributed throughout the year, showing no seasonal bias, and the annual evaporation is well represented (Fig. 7a,V0). A sensitivity study was performed, considering the near-surface stability (V1), using the stability factors after Cline (1997). However, the comparison with V0 shows that the inclusion of the stability has a negligible effect (Table 6).

The BREB method is first used in the simplified version shown in Table 1, neglecting net advected heat fluxes, the ground heat flux, and the heat storage term. With this version (V0), only net radiation, surface water temperature, and air temperature have to be known. These variables are relatively easy to obtain and it would therefore be an easy approach to calculate evaporation. However, neglecting the heat storage term results in a strong bias of the evaporation rates. The correlation coefficients range from only 0.67 for $1 \mathrm{~d}$ time intervals to 0.87 for $28 \mathrm{~d}$ intervals, the slope varies from 1.27 to 1.72 , respectively, and the largest offset is $-1.35 \mathrm{mmd}^{-1}$ (Table 6). This indicates a strong overestimation of high evaporation rates in spring and summer and an underestimation of small evaporation rates mainly in winter (Fig. 6b,V0), resulting in a clear seasonal bias. From April until September daily evaporation rates are overestimated by up to $3 \mathrm{~mm} \mathrm{~d}^{-1}$ and underestimated during the rest of the year (Fig. 7b,V0). This seasonal bias was also observed in other studies, e.g. Winter et al. (1995); Rosenberry et al. (2007). Compared to the measured values, this results in an overestimation of the annual evaporation by $22 \%$, calculated from the $28 \mathrm{~d}$ averages. For the other time intervals the overestimation of the annual evaporation was comparable and is therefore not shown. The sensitivity study V2, considers the heat storage of the lake using a hysteresis model. Correlation coefficients are better and the mean differences are reduced (Table 6). However, the slope and offset shows that the heat storage term is still not represented correctly. The slopes and the offsets indicate an overestimation of small evaporation rates and an underestimation of high evaporation rates (Fig. 6b,V2). The intra-annual performance improved slightly and evaporation estimates between November and April are quite good; however, evaporation rates are underestimated in summer and autumn by about $1 \mathrm{mmd}^{-1}$ (Fig. 7b,V2). This results in a underestimation of the annual evaporation by about $11 \%$. Sensitivity study V3 also 
Table 6. Slope and offset of the regression lines between the evaporation estimates calculated with the different equations and the evaporation measurements and the corresponding correlation coefficient $(R)$, for averaging periods of $30 \mathrm{~min}, 1,7,14$, and 28 days. Mean difference (MD) and standard deviation (SD) in $\mathrm{mm} \mathrm{d}^{-1}$ are shown for 1 and $28 \mathrm{~d}$ as no relevant differences for the other time intervals exist. V0 to V6 indicate the different sensitivity studies (see Table 2). The best fitting solutions are indicated with bold numbers.

\begin{tabular}{|c|c|c|c|c|c|c|c|c|c|c|c|c|c|c|c|c|c|c|}
\hline & & \multicolumn{5}{|c|}{ Slope } & \multicolumn{5}{|c|}{ Offset } & \multicolumn{5}{|c|}{$R$} & \multicolumn{2}{|c|}{$\mathrm{MD} \pm \mathrm{SD}$} \\
\hline & & $30 \mathrm{~min}$ & $1 \mathrm{~d}$ & $7 d$ & $14 \mathrm{~d}$ & $28 \mathrm{~d}$ & $30 \mathrm{~min}$ & $1 \mathrm{~d}$ & $7 d$ & $14 \mathrm{~d}$ & $28 \mathrm{~d}$ & $30 \mathrm{~min}$ & $1 \mathrm{~d}$ & $7 d$ & $14 \mathrm{~d}$ & $28 \mathrm{~d}$ & $1 \mathrm{~d}$ & $28 \mathrm{~d}$ \\
\hline \multirow{2}{*}{$\begin{array}{l}\text { Aero- } \\
\text { dynamic }\end{array}$} & Vo & 1.26 & 1.13 & 1.08 & 1.10 & 1.12 & -0.01 & -0.33 & -0.24 & -0.29 & -0.34 & 0.85 & 0.94 & 0.94 & 0.98 & 0.99 & $0.02 \pm 0.54$ & $-0.02 \pm 0.24$ \\
\hline & $\mathrm{V} 1$ & 1.27 & 1.16 & 1.10 & 1.13 & 1.14 & -0.01 & -0.30 & -0.17 & -0.23 & -0.26 & 0.85 & 0.94 & 0.94 & 0.98 & 0.99 & $0.13 \pm 0.54$ & $0.11 \pm 0.24$ \\
\hline \multirow[t]{3}{*}{ BREB } & V0 & - & 1.27 & 1.51 & 1.63 & 1.72 & - & -0.13 & -0.78 & -1.11 & -1.35 & & 0.67 & 0.78 & 0.84 & 0.87 & $0.60 \pm 1.78$ & $0.61 \pm 1.26$ \\
\hline & V2 & - & 0.45 & 0.57 & 0.63 & 0.67 & - & 1.21 & 0.89 & 0.70 & 0.59 & - & 0.69 & 0.83 & 0.90 & 0.96 & $-0.30 \pm 0.89$ & $-0.30 \pm 0.40$ \\
\hline & V3 & - & 1.17 & 1.39 & 1.50 & 1.58 & - & -0.12 & -0.72 & -1.02 & -1.24 & - & 0.67 & 0.78 & 0.84 & 0.87 & $0.33 \pm 1.62$ & $0.33 \pm 1.11$ \\
\hline \multirow{3}{*}{$\begin{array}{l}\text { Priestley- } \\
\text { Taylor }\end{array}$} & V0 & - & 1.35 & 1.61 & 1.74 & 1.84 & - & -0.28 & -0.98 & -1.33 & -1.58 & - & 0.69 & 0.80 & 0.86 & 0.89 & $0.69 \pm 1.81$ & $0.70 \pm 1.30$ \\
\hline & $\mathrm{V} 2$ & - & 0.49 & 0.62 & 0.70 & 0.74 & - & 1.17 & 0.81 & 0.59 & 0.47 & - & 0.73 & 0.87 & 0.93 & 0.98 & $-0.24 \pm 0.84$ & $-0.23 \pm 0.32$ \\
\hline & V3 & - & 1.17 & 1.39 & 1.51 & 1.59 & - & -0.24 & -0.85 & -1.15 & -1.37 & - & 0.69 & 0.80 & 0.86 & 0.89 & $0.23 \pm 1.53$ & $-0.24 \pm 1.04$ \\
\hline \multirow[t]{7}{*}{ Penman } & V0 & - & 1.44 & 1.58 & 1.69 & 1.76 & - & 0.19 & -0.20 & -0.49 & -0.69 & - & 0.78 & 0.83 & 0.88 & 0.91 & $1.38 \pm 1.52$ & $1.38 \pm 1.17$ \\
\hline & V1 & - & 1.44 & 1.57 & 1.68 & 1.76 & - & 0.24 & -0.12 & -0.41 & -0.61 & - & 0.78 & 0.83 & 0.88 & 0.91 & $1.44 \pm 1.52$ & $1.45 \pm 1.16$ \\
\hline & $\mathrm{V} 2$ & - & 0.75 & 0.80 & 0.85 & 0.89 & - & 1.34 & 1.21 & 1.04 & 0.94 & - & 0.87 & 0.89 & 0.94 & 0.97 & $0.65 \pm 0.61$ & $0.64 \pm 0.25$ \\
\hline & V3 & - & 0.94 & 0.99 & 1.05 & 1.09 & - & 0.29 & 0.16 & 0.00 & -0.11 & - & 0.82 & 0.84 & 0.90 & 0.92 & $0.13 \pm 0.82$ & $0.13 \pm 0.51$ \\
\hline & V4 & - & 1.54 & 1.73 & 1.80 & 1.87 & - & 0.45 & -0.09 & -0.28 & -0.48 & - & 0.89 & 0.91 & 0.94 & 0.96 & $1.92 \pm 1.16$ & $1.91 \pm 1.07$ \\
\hline & V5 & - & 0.96 & 1.01 & 1.04 & 1.06 & - & 1.22 & 1.10 & 1.00 & 0.93 & - & 0.92 & 0.93 & 0.96 & 0.97 & $1.10 \pm 0.51$ & $1.10 \pm 0.27$ \\
\hline & V6 & - & 0.78 & 0.80 & 0.81 & 0.84 & - & 0.59 & 0.54 & 0.49 & 0.42 & - & 0.92 & 0.92 & 0.95 & 0.97 & $-0.02 \pm 0.50$ & $-0.02 \pm 0.29$ \\
\hline
\end{tabular}

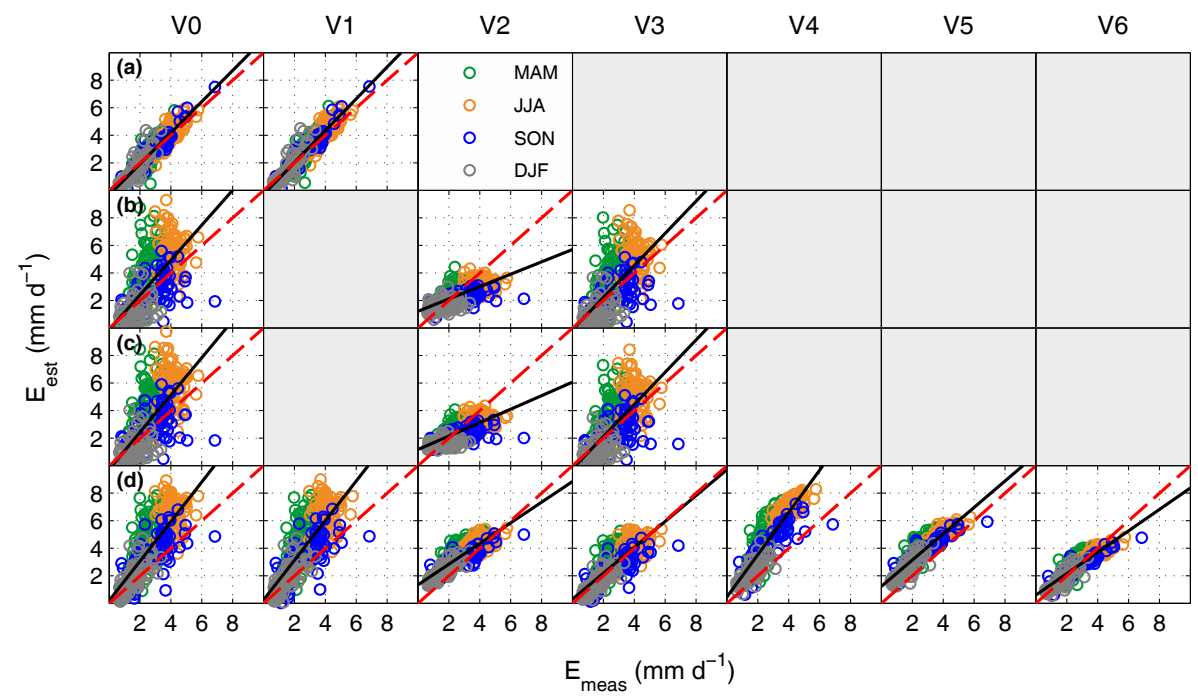

Figure 6. Correlation between estimated and measured daily evaporation rates for (a) the aerodynamic approach, (b) the BREB method, (c) the Priestley-Taylor equation, and (d) the Penman equation and their sensitivity studies (Table 2) calculated from $1 \mathrm{~d}$ averages. The colours indicate the meteorological seasons spring (MAM), summer (JJA), autumn (SON), and winter (DJF). The regression line is shown in black and the $1: 1$ line as a dashed red line.

accounts for the heat storage term by using $\Delta Q=0.08 \cdot R_{\mathrm{n}}$, derived from the deviation of $\mathrm{V} 0$ from the measurements. This approach can only slightly improve the correlation coefficient, slope, offset, and mean difference in comparison to V0 (Table 6). Only the annual evaporation improves compared to the default version and overestimates evaporation by only $13 \%$ instead of $22 \%$ (Fig. 7b,V3).

The Priestley-Taylor equation, as described in (Table 6), results in correlation coefficients between 0.69 for $1 \mathrm{~d}$ and 0.89 for $28 \mathrm{~d}$ time intervals. Like the BREB equation, slopes are too high with values between 1.35 and 1.84 and offsets vary between -0.28 and $-1.58 \mathrm{mmd}^{-1}$ (Table 6). By neglecting the heat storage term small evaporation rates are underestimated and large ones overestimated (Fig. 6c,V0), resulting in a strong seasonal bias and an overestimation of the annual evaporation by $26 \%$ (Fig. 7c,V0). Sensitivity test V2 yields similar results as for the BREB equation (Table 6). With the hysteresis model the seasonal bias shifts to an underestimation of evaporation in summer and autumn and relatively good results for winter and spring, resulting in a total underestimation of the annual evaporation by $8 \%$ (Fig. 7c,V2). In V3 the heat storage is considered as a linear function of $R_{\mathrm{n}}$ and, thus, results in a new Priestley-Taylor coefficient of 1.09. With V3 the seasonal bias is reduced but high evaporation rates are still overestimated and low ones 


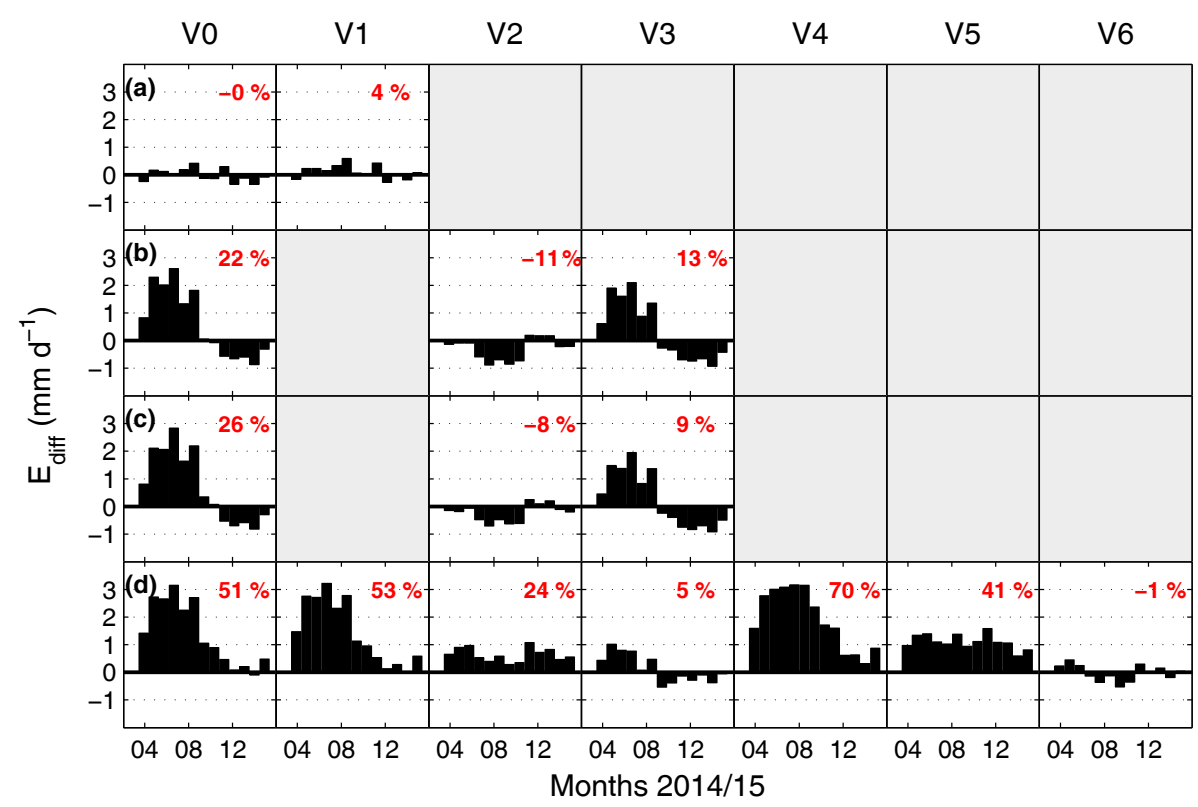

Figure 7. Differences between the estimated daily evaporation rates calculated from the $28 \mathrm{~d}$ time averages and the measured daily evaporation rates for (a) the aerodynamic approach, (b) the BREB method, (c) the Priestley-Taylor equation, (d) the Penman equation, and their sensitivity studies (Table 2). The red numbers show the total deviation of the accumulated calculated annual evaporation ( $28 \mathrm{~d}$ averages) from the accumulated measured evaporation.

underestimated (Table 6). The annual evaporation is overestimated by $9 \%$ (Fig. 7c,V3).

The last equation tested is the Penman equation. In its original form (Table 6, V0) it results in correlation coefficients of 0.78 for time averages of $1 \mathrm{~d}$ to 0.91 for $28 \mathrm{~d}$ (Table 6). However, the slopes of the regression lines vary between 1.44 and 1.76, respectively, and indicate an overestimation. The mean differences also show a strong variability. Evaporation rates are strongly overestimated from spring until autumn (Fig. 6d,V0), exceeding the measured daily evaporation rates by up to $100 \%$ (compare Fig. 7 d,V0 to Fig. 5). The annual evaporation is thus also overestimated by $51 \%$ showing that the original Penman equation is not applicable for the investigation of intra-annual variations. The consideration of the heat storage using the hysteresis model (V2) yields considerable improvements regarding the correlation coefficient. Its value varies between 0.87 and 0.97 , and the mean difference and its standard deviation is reduced, meaning that the spread of the calculated values is smaller (Table 6). The slopes for $\mathrm{V} 2$ are all below unity and the offsets above $0.94 \mathrm{~mm} \mathrm{~d}^{-1}$, meaning that small evaporation rates are overestimated (Fig. 6d,V2). This is also apparent in the intraannual deviation of the estimated evaporation rates from the measured ones. Deviations are below or around $1 \mathrm{mmd}^{-1}$ for all months, resulting in a total overestimation of the annual evaporation by $24 \%$ (Fig. 7d,V2).

The calculation of the heat storage term as a linear function of the net radiation results in $\Delta Q=0.46 \cdot R_{\mathrm{n}}$. Using this function for the heat storage term in V3, the results are strongly improved. The slopes of the regression lines are close to one, offsets are small, and also the mean differences are smaller (Table 6). Correlation coefficients vary between 0.82 and 0.92 and the annual evaporation is only overestimated by $5 \%$, which is in the range of the measurement uncertainties. However, the results show a seasonal bias with an overestimation in spring and summer and a underestimation in autumn and winter (Fig. 7d,V3).

Another commonly used variation of the Penman equation is the removal of the surface water temperature from the calculation of the net radiation. This is tested in V4. However, in V4 the heat storage term is still missing an thus does not result in reliable evaporation rates (Figs. 6 and 7d,V4). The combination of the hysteresis model with the removal of the surface water temperature (V5) yields an improvement of the correlation coefficients, the slope of the regression lines, and also the standard deviations, but the calculated rates show an offset of over $0.93 \mathrm{~mm} \mathrm{~d}^{-1}$ (Table 6). This results in a constant overestimation of evaporation rates throughout the year and results in an annual evaporation which is $41 \%$ higher than the measured one (Fig. 7d,V5). The last test for the Penman equation combines the removal of the surface water temperature with a derived linear function for the heat storage term from $\mathrm{V} 4$. With a heat storage term $\Delta Q=0.77 \cdot R_{\mathrm{n}}$ the discrepancy of the calculated from the measured rates can be minimised. The regression line is still slightly tilted (Fig. 6d,V6), small evaporation rates are overestimated, and large ones underestimated, but the mean difference is nearly zero and the standard deviation is in the range of 0.29 to 
$0.5 \mathrm{~mm} \mathrm{~d}^{-1}$ (Table 6). The annual evaporation is well represented with this adjustments of the equation (Fig. 7d,V6).

\section{Discussion and conclusion}

The eddy covariance method is used for the first highresolution, direct evaporation measurements of the Dead Sea. The first aim of this study was to present an applicable method to measure evaporation with a shoreline station. The measurement strategy is based on the installation of the station on a headland, surrounded by water from $320^{\circ}$. The advantage of this setup at the shoreline is the avoidance of raft motion and sea spray influencing the measurements, where the latter one leads to a serious soiling of the instrument and influences data quality strongly. The major drawback of land-based eddy covariance measurements is the limited data availability of measured lake evaporation as part of the flux footprint is located over land. In this study $19 \%$ and in other works 15-25\% (e.g. Mammarella et al., 2015; Nordbo et al., 2011) of the data were rejected due to the fetch criteria. This was overcome by a novel approach. A multiple regression model was trained with the onshore wind and vapour pressure deficit data. With this model lake evaporation for offshore wind conditions was calculated and, thus, data availability was increased from 59.2 to $76.8 \%$. The uncertainty introduced by this method is small with a prediction error of the calculated values of $4.8 \%$, making it a very reliable method. However, there is still some uncertainty due to this method which cannot be accounted for directly. On the one hand, extreme values of wind velocity and water vapour pressure deficit were not used to calculate evaporation when they were outside the model boundaries. This leads most likely to an underestimation of the actual evaporation rate. On the other hand, wind velocity and vapour pressure deficit could decrease with increasing distance from the shoreline, which would lead to an overestimation of evaporation. However, the comparison with results from measurements in the middle of the lake (Weiss et al., 1988; Hecht and Gertman, 2003) shows that even in the middle of the lake westerly winds with hourly averaged velocities between 8 and $12 \mathrm{~m} \mathrm{~s}^{-1}$ were observed. Wind lidar measurements confirmed that the westerly winds regularly reach several $\mathrm{km}$ over the lake without loosing their strength (Metzger, 2017). In conclusion, offshore wind measurements seem representative for lake conditions and reasonable for the calculation of evaporation. A decrease in vapour pressure deficit has to be considered but is most likely small for the following reasons. Firstly, the fetch of the station is limited to $600 \mathrm{~m}$, meaning that the distance the air mass passes over the water is short. Secondly, the westerly winds are connected with high turbulence and, thus, strong vertical mixing (Metzger, 2017). From these results we conclude that the approach is also applicable to other lakes, in the case where the measured onshore wind velocity and vapour pressure deficit values are representative for offshore conditions to appropriately train the model, and the fetch of the flux measurements is small enough that the meteorological measurements at the shoreline are representative for the fetch.

The second aim was to evaluate the diurnal and intraannual variability of Dead Sea evaporation. The annual Dead Sea evaporation was found to be $994 \pm 88.2 \mathrm{~mm}$ for the measurement period. The uncertainty of $8.8 \%$ results mostly from the gap-filling procedure $(81.2 \mathrm{~mm})$ and not from the regression model. As gaps result from system malfunction or bad data quality, the uncertainty can be reduced by improving the system performance or by finding a better method to fill the gaps. The annual evaporation coincides well with previous findings such as Stanhill (1994) with $1005 \mathrm{~mm} \mathrm{a}^{-1}$ and is close to the results from Lensky et al. (2005) (1100$1200 \mathrm{~mm} \mathrm{a}^{-1}$ ), which both estimated the evaporation based on theoretical energy budget approaches. A certain degree of differences between the results is inevitable as the studies considered different data sets and different time periods, meaning different water salinities and different weather conditions. However, the measurements are far away from the $2000 \mathrm{~mm}$ from Salameh and El-Naser (1999), who estimated evaporation based on water budget calculations, which could indicate uncertainties in the assessment of the water budget components. Therefore, the results could be implemented into hydrological models to study the uncertain water budget components and the development of the water budget in the future. Furthermore, the results show that the diurnal cycle of evaporation is in phase with the wind velocity, which corresponds to findings of other studies in the Jordan Valley (e.g. Assouline, 1993; Assouline et al., 2008). As a result the strong westerly winds in the evening double evaporation compared to midday values. These findings are also important for other lakes, where strong and dry wind systems are observed, e.g. bora, tramontane, mistral. Bouin et al. (2012) showed that the tramontane in France trebles evaporation from a lagoon compared to non-tramontane conditions. In respect of ongoing climate change our results could motivate a regional study on the impact of climate change on the future evolution of thermally and orographically induced wind systems in the Mediterranean region. So far, there is little information, although it is important for the future development of the water bodies. As expected, Dead Sea evaporation is lower compared to other less and non-saline lakes. The ratio to Lake Kinneret, which is located only $100 \mathrm{~km}$ north, is 0.68 in summer but only 0.83 in winter. This difference is most likely caused by the different climatic conditions in winter. Lake Kinneret receives a considerable amount of rainfall due to more humid air masses as it is located within a Mediterranean climate zone (Goldreich, 2003), whereas the Dead Sea has arid climate, where, even in winter, very little rainfall occurs.

For the prospective affordable long-term assessment of evaporation, different equations to calculate evaporation were tested for their applicability for the Dead Sea. The best 
suitable, and also the only method applicable on sub-daily timescales, is the aerodynamic approach. It is shown that the consideration of the atmospheric stability in the calculations has a negligible effect on the results. These results coincide with results for Lake Kinneret (Shilo et al., 2015; Rimmer et al., 2009) and make this method easily applicable for evaporation calculations applying data from a shoreline station. The other approaches are developed for longer time intervals and are not applicable for sub-daily calculations. The results also confirm the findings from various other studies (Rimmer et al., 2009; Giadrossich et al., 2015; Tanny et al., 2008; Rosenberry et al., 2007) that for the BREB, Priestley-Taylor, and Penman method, the knowledge of the heat storage term is essential to achieve reliable results, as neglecting the heat storage results in a strong seasonal bias. Using estimates of the heat storage term does not provide acceptable results for the BREB or for the Priestley-Taylor method. For the Penman equation, an applicable solution is achieved when using the empirically gained function for the heat storage. Thus, we conclude that the BREB and Priestley-Taylor method are not applicable with data from a shoreline station, but the aerodynamic and the adapted Penman method can be used, making expensive raft measurements expendable. For future application it is advisable to use the Penman method only for longer time intervals as its prediction skill improves with increasing time interval and to use the aerodynamic method for short time intervals. The use of low-maintenance, cost-efficient measurements to estimate evaporation on short timescales is beneficial for economic purposes, such as the production of minerals from the saline water, as well as for further investigations of the water budget of the lake. For instance, pumping rates for mineral production can be adjusted according to the evaporation rates.

Data availability. Metadata for all measurements are publicly available via https://www.deserve-vi.net/index.php/publications (Nied, 2016). Data can be accessed by contacting the responsible person given in the metadata. 


\section{Appendix A: Calculation of surface water temperature}

The surface water temperature $T_{\mathrm{s}}$ was not measured and could also not be retrieved from satellite data. Therefore, it was calculated following Monin-Obukhov's similarity approach:

$T_{\mathrm{MO}}=T_{\mathrm{s}}=T\left(z_{\mathrm{m}}\right)-\frac{\theta^{*}}{\kappa} \cdot\left(\ln \frac{z_{\mathrm{m}}}{z_{0}}-\Psi_{H}\left(\zeta_{\mathrm{m}}, \zeta_{0}\right)\right)$.

$T_{\mathrm{MO}}$ is the calculated surface water temperature at the height of the roughness length $z_{0}$, which is assumed as $0.001 \mathrm{~m}$; $z_{\mathrm{m}}$ is the measurement height in $\mathrm{m} ; \zeta_{\mathrm{m}}=z_{\mathrm{m}} L_{*}^{-1}$ and $\zeta_{0}=$ $z_{0} L_{*}^{-1}$ are independent dimensionless parameters using the Monin-Obukhov length $L_{*}$; and $\frac{\theta^{*}}{\kappa}$ is a scaling parameter defined as

$\frac{\theta^{*}}{\kappa}=-\frac{1}{\kappa u^{*}} \frac{H}{\rho_{0} c_{\mathrm{p}}}$,

with $\kappa=0.4$, which is the Kármán constant; sensible heat flux $H$ in $\mathrm{Wm}^{-2}$; specific heat capacity $c_{\mathrm{p}}=$ $1004 \mathrm{~J} \mathrm{~K}^{-1} \mathrm{~kg}^{-1}$; and density of the air $\rho_{0}$ in $\mathrm{kg} \mathrm{m}^{-3} . \Psi_{H}$ is the integral over the empirical gained functions $\varphi_{H}$ :

$\Psi_{H}\left(\zeta_{\mathrm{m}}, \zeta_{0}\right)=\int_{z_{0}}^{z_{\mathrm{m}}}=\frac{1-\varphi_{H}}{z} \mathrm{~d} z$.

In this work the $\varphi$ functions from Dyer (1974) are used:
$\varphi_{H}=1+5 \zeta$
$\zeta>0$,
$\varphi_{H}=(1-16 \zeta)^{-1 / 2}$
$-1<\zeta<0$

\section{Appendix B: Measurement of the latent heat of vaporisation}

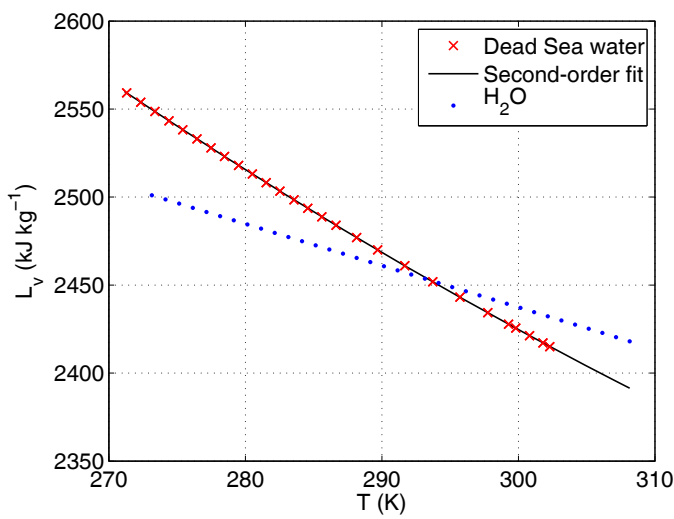

Figure B1. Dependency of the specific latent heat of vaporisation $\left(L_{\mathrm{V}}\right)$ on temperature. Measurements of $L_{\mathrm{V}}$ for the saline water of the Dead Sea, a second-order polynomial fit, and literature values for pure water $\left(\mathrm{H}_{2} \mathrm{O}\right)$ are shown.

The latent heat of vaporisation and the activity of water $\beta$ for the highly saline water of the Dead Sea were measured using a water probe taken at the measurement site of the EBS at the end of 2014. First, the saturation vapour pressure of pure water $E_{\mathrm{w}}$ was measured with a capacitance manometer, which was calibrated by a linear regression to literature values (Weast et al., 1987). Afterwards, the saturation vapour pressure of the saline water, $E_{\mathrm{S}}$, was measured as a function of water temperature with the calibrated manometer. Through this approach possible measurement uncertainties of the manometer could be minimised. The activity of water can then be calculated as

$\beta=\frac{E_{\mathrm{s}}}{E_{\mathrm{w}}}$.

The averaged activity for the Dead Sea water is $\beta=0.65$

The molar latent heat of vaporisation, $\Delta H_{\mathrm{vap}}\left(\mathrm{J} \mathrm{mol}^{-1}\right)$, can be derived by using the general form of the ClausiusClapeyron equation, assuming that the molar volume of the liquid can be neglected against the molar volume of the gas, and by using the ideal gas law:

$\Delta H_{\text {vap }}=-R \frac{\mathrm{d}\left(\ln E_{\mathrm{s}}\right)}{\mathrm{d}\left(\frac{1}{T_{\mathrm{w}}}\right)}$.

$R=8.314 \mathrm{~J} \mathrm{~mol}^{-1} \mathrm{~K}^{-1}$ is the universal gas constant, the corrected saturation vapour pressure of the saline water is $E_{\mathrm{s}}$ in $\mathrm{hPa}$, and water temperature is $T_{\mathrm{w}}$ in $\mathrm{K}$. With the molar mass of water $m_{\mathrm{H}_{2} \mathrm{O}}=0.018 \mathrm{~kg} \mathrm{~mol}^{-1}$, the specific latent heat of vaporisation $L_{\mathrm{v}}$ can be calculated,

$L_{\mathrm{v}}=\frac{\Delta H_{\mathrm{vap}}}{m_{\mathrm{H}_{2} \mathrm{O}} \cdot 1000}$, 
in $\mathrm{kJ} \mathrm{kg}^{-1}$, and can then be fitted to the water temperature $T_{\mathrm{w}}$ (Fig. B1). The regression formula is

$L_{\mathrm{v}}=5150.6561-13.9530 \cdot T_{\mathrm{w}}+0.0162 \cdot T_{\mathrm{w}}^{2}$.

\section{Appendix C: Calculation of vapour pressure deficit}

The vapour pressure deficit for the regression approach is calculated as follows. The vapour pressure deficit is defined as the difference between the saturation vapour pressure above the saline water, $E_{\mathrm{s}}$, and the atmospheric vapour pressure at $2 \mathrm{~m}$ height, $e_{\mathrm{a}, 2 \mathrm{~m}}$ :

$\Delta e=E_{\mathrm{s}}-e_{\mathrm{a}, 2 \mathrm{~m}}$.

The saturation vapour pressure of saline water is lower than that of freshwater, $E_{\mathrm{w}}$, by a factor $\beta$, caused by the vapour pressure depression by dissolved salts (Raoult's law) (Atkins, 2014).

$E_{\mathrm{s}}=\beta \cdot E_{\mathrm{w}}$.

The activity $\beta$ depends on the composition of the dissolved salts and is determined to 0.65 for the Dead Sea water in this study (Appendix B). Saturation vapour pressure over water can be calculated using the Magnus equation after Bolton (1980):

$E_{\mathrm{w}}\left(T_{\mathrm{S}}\right)=6.112 \cdot \exp \left(\frac{17.67 \cdot\left(T_{\mathrm{S}}-273.15\right)}{T_{\mathrm{S}}-29.65}\right)$,

with surface water temperature $T_{\mathrm{S}}$ in $\mathrm{K}$. As surface water temperature is not directly measured at the station, vapour pressure deficit is calculated using surface water temperature obtained by the Monin-Obukhov theory, $T_{\mathrm{MO}}$, in $\mathrm{K}$ :

$\Delta e_{\mathrm{MO}}=\beta \cdot E_{\mathrm{w}}\left(T_{\mathrm{MO}}\right)-e_{\mathrm{a}, 2 \mathrm{~m}}$. 
Competing interests. The authors declare that they have no conflict of interest.

Special issue statement. This article is part of the special issue "Environmental changes and hazards in the Dead Sea region (NHESS/ACP/HESS/SE inter-journal SI)". It is not associated with a conference.

Acknowledgements. The current study was carried out in the framework of the Dead Sea Research Venue (DESERVE) (http://www.deserve-vi.net), an international project funded by the Helmholtz Association of German Research Centres as a Virtual Institute (VH-VI-527). We would like to thank Bernhard Deny and Philipp Gasch for maintaining the stations. We thank Pinhas Alpert and Eduard Karat from Tel Aviv University for their support. We also want to thank David Seveloff and Yael Maor from the Dead Sea and Arava Science Center for their support with the measurements and Ein Gedi Spa for the provision of the measurement location. The authors also thank the editor and four anonymous referees for their insightful remarks which helped to improve the paper.

The article processing charges for this open-access publication were covered by a Research

Centre of the Helmholtz Association.

Edited by: Matthew Hipsey

Reviewed by: four anonymous referees

\section{References}

Abelson, M., Yechieli, Y., Crouvi, O., Baer, G., Wachs, D., Bein, A., and Shtivelman, V.: Evolution of the Dead Sea sinkholes, Geol. Soc. Spec. Pap., 401, 241-253, 2006.

Alpert, P., Shafir, H., and Issahary, D.: Recent changes in the climate at the Dead Sea - a preliminary study, Climatic Change, 37, 513537, https://doi.org/10.1023/A:1005330908974, 1997.

Arkin, Y. and Gilat, A.: Dead Sea sinkholes - an ever-developing hazard, Environ. Geol., 39, 711-722, 2000.

Asmar, B. and Ergenzinger, P.: Dynamic simulation of the Dead Sea, Adv. Water Resour., 25, 263-277, 2002.

Asmar, B. N. and Ergenzinger, P.: Estimation of evaporation from the Dead Sea, Hydrol. Process., 13, 2743-2750, https://doi.org/10.1002/(SICI)10991085(19991215)13:17<2743::AID-HYP845>3.0.CO;2-U, 1999.

Assouline, S.: Estimation of lake hydrologic budget terms using the simultaneous solution of water, heat, and salt balances and a Kalman Filtering Approach: Application to Lake Kinneret, Water Resour. Res., 29, 3041-3048, https://doi.org/10.1029/93WR01181, 1993.

Assouline, S. and Mahrer, Y.: Evaporation from Lake Kinneret: 1. Eddy correlation system measurements and energy budget estimates, Water Resour. Res., 29, 901-910, 1993.

Assouline, S., Tyler, S., Tanny, J., Cohen, S., Bou-Zeid, E., Parlange, M., and Katul, G.: Evaporation from three water bodies of different sizes and climates: Measurements and scaling analysis, Adv. Water Resour., 31, 160-172, 2008.

Atkins, P.: Physical Chemistry, 10 edn., Oxford Univ. Press, Oxford, 2014.

Bitan, A.: The wind regime in the north-west section of the Dead-Sea, Arch. Meteor. Geophy. B, 22, 313-335, https://doi.org/10.1007/BF02246585, 1974.

Bitan, A.: The influence of the special shape of the Dead-Sea and its environment on the local wind system, Arch. Meteor. Geophy. B, 24, 283-301, 1976.

Blanken, P. D., Rouse, W. R., Culf, A. D., Spence, C., Boudreau, L. D., Jasper, J. N., Kochtubajda, B., Schertzer, W. M., Marsh, P., and Verseghy, D.: Eddy covariance measurements of evaporation from Great Slave Lake, Northwest Territories, Canada, Water Resour. Res., 36, 1069-1077, https://doi.org/10.1029/1999WR900338, 2000.

Bolton, D.: The computation of equivalent potential temperature, Mon. Weather Rev., 108, 1046-1053, 1980.

Bouin, M.-N., Caniaux, G., Traulle, O., Legain, D., and Le Moigne, P.: Long-term heat exchanges over a Mediterranean lagoon, J. Geophys. Res.-Atmos., 117, https://doi.org/10.1029/2012JD017857, 2012.

Brutsaert, W.: Evaporation into the Atmosphere. Theory, History, and Applications, Reidel, Dordrecht, the Netherlands, 1982.

Calder, I. and Neal, C.: Evaporation from saline lakes: a combination equation approach, Hydrolog. Sci. J., 29, 89-97, 1984.

Cline, D. W.: Snow surface energy exchanges and snowmelt at a continental, midlatitude Alpine site, Water Resour. Res., 33, 689-701, 1997.

Dingman, S.: Physical Hydrology, Physical Hydrology, 2nd edn., Prentice Hall, Upper Saddle River, New Jersey, 2002.

Duan, Z. and Bastiaanssen, W.: A new empirical procedure for estimating intra-annual heat storage changes in lakes and reservoirs: review and analysis of 22 lakes, Remote Sens. Environ., 156 , 143-156, 2015.

Dyer, A.: A review of flux-profile relationships, Bound.-Lay. Meteorol., 7, 363-372, https://doi.org/10.1007/BF00240838, 1974.

Emery, W., Castro, S., Wick, G., Schluessel, P., and Donlon, C.: Estimating sea surface temperature from infrared satellite and in situ temperature data, B. Am. Meteorol. Soc., 82, 2773, https://doi.org/10.1175/15200477(2001)082<2773:ESSTFI>2.3.CO;2, 2001.

Foken, T.: Der Bayreuther Turbulenzknecht, Tech. Rep. 1, Univ. Bayreuth, Abt. Mikrometeorol., Bayreuth, 16 pp., 1999.

Foken, T.: The energy balance closure problem: an overview, Ecol. Appl., 18, 1351-1367, 2008.

Foken, T. and Wichura, B.: Tools for quality assessment of surfacebased flux measurements, Agr. Forest Meteorol., 78, 83-105, https://doi.org/10.1016/0168-1923(95)02248-1, 1996.

Foken, T., Leuning, R., Oncley, S., Mauder, M., and Aubinet, M.: Corrections and data quality control, in: Eddy Covariance. A Practical Guide to Measurements and Data Analysis, edited by: Aubinet, M., Vesala, T., and Papale, D., Springer, Dordrecht, 85132, 2012.

Giadrossich, F., Niedda, M., Cohen, D., and Pirastru, M.: Evaporation in a Mediterranean environment by energy budget and Penman methods, Lake Baratz, Sardinia, Italy, Hydrol. Earth Syst. Sci., 19, 2451-2468, https://doi.org/10.5194/hess-19-2451-2015, 2015. 
Givati, A. and Tal, A.: Monthly hydrological status: upper water in major drainage areas and water tables in the country system, The Hydrological Service and Water Authority, Israel, 2016.

Goldreich, Y.: The Climate of Israel: Observation, Research, and Application, Kluwer Academic/Plenum Publishers, New York (u.a.), 2003.

Goren, M. and Ortal, R.: Biogeography, diversity and conservation of the inland water fish communities in Israel, Biol. Conserv., 89, 1-9, https://doi.org/10.1016/S0006-3207(98)00127-X, 1999.

Hecht, A. and Gertman, I.: Dead Sea meteorological climate, in: Fungal Life in the Dead Sea, edited by: Nevo, E., Oren, A., and Wasser, S., International Center for Cryptogamic Plants and Fungi, Haifa, 68-114, 2003.

Henderson-Sellers, B.: Calculating the surface energy balance for lake and reservoir modeling: a review, Rev. Geophys., 24, 625649, 1986.

Holtzman, R., Shavit, U., Segal-Rozenhaimer, M., Gavrieli, I., Marei, A., Farber, E., and Vengosh, A.: Quantifying ground water inputs along the lower Jordan River, J. Environ. Qual., 34, 897-906, 2005.

Jonsson, A., Åberg, J., Lindroth, A., and Jansson, M.: Gas transfer rate and $\mathrm{CO}_{2}$ flux between an unproductive lake and the atmosphere in northern Sweden, J. Geophys. Res.-Biogeo., 113, https://doi.org/10.1029/2008JG000688, 2008.

Kljun, N., Calanca, P., Rotach, M. W., and Schmid, H. P.: A simple two-dimensional parameterisation for Flux Footprint Prediction (FFP), Geosci. Model Dev., 8, 3695-3713, https://doi.org/10.5194/gmd-8-3695-2015, 2015.

Kohler, M. and Parmele, L.: Generalized estimates of free-water evaporation, Water Resour. Res., 3, 997-1005, 1967.

Konda, M., Imasato, N., Nishi, K., and Toda, T.: Measurement of the sea surface emissivity, J. Oceanogr., 50, 17-30, 1994.

Kondrat'Ev, K. Y.: Radiation in the Atmosphere, International Geophysics Series, Vol. 12, Academic Press, New York, 1969.

Kottmeier, C., Agnon, A., Al-Halbouni, D., Alpert, P., Corsmeier, U., Dahm, T., Eshel, A., Geyer, S., Haas, M., Holohan, E., Kalthoff, N., Kishcha, P., Krawczyk, C., Lati, J., Laronne, J. B., Lott, F., Mallast, U., Merz, R., Metzger, J., Mohsen, A., Morin, E., Nied, M., Rödiger, T., Salameh, E., Sawarieh, A., Shannak, B., Siebert, C., and Weber, M.: New perspectives on interdisciplinary earth science at the Dead Sea: The DESERVE project, Sci. Total Environ., 544, 1045-1058, 2016.

Lensky, N. G., Dvorkin, Y., Lyakhovsky, V., Gertman, I., and Gavrieli, I.: Water, salt, and energy balances of the Dead Sea, Water Resour. Res., 41, 1-13, https://doi.org/10.1029/2005WR004084, 2005.

Lipchin, C., Sandler, D., and Cushman, E.: The Jordan River and Dead Sea Basin: Cooperation Amid Conflict, Springer Science and Business Media, Dordrecht, the Netherlands, 2009.

Mammarella, I., Nordbo, A., Rannik, Ü., Haapanala, S., Levula, J., Laakso, H., Ojala, A., Peltola, O., Heiskanen, J., Pumpanen, J., and Vesala, T.: Carbon dioxide and energy fluxes over a small boreal lake in Southern Finland, J. Geophys. Res.-Biogeo., 120, 1296-1314, 2015.

Mauder, M. and Foken, T.: Documentation and instruction manual of the eddy-covariance software package TK3, vol. 46, Univ. Bayreuth, Abt. Mikrometeorologie, Bayreuth, 2011.
Mauder, M., Cuntz, M., Drüe, C., Graf, A., Rebmann, C., Schmid, H. P., Schmidt, M., and Steinbrecher, R.: A strategy for quality and uncertainty assessment of long-term eddycovariance measurements, Agr. Forest Meteorol., 169, 122-135, https://doi.org/10.1016/j.agrformet.2012.09.006, 2013.

Metzger, J. V.: Wind systems and energy balance in the Dead Sea Valley, Wissenschaftliche Berichte des Instituts für Meteorologie und Klimaforschung des Karlsruher Instituts für Technologie; Band 74, KIT Scientific Publishing, Karlsruhe, 2017.

Naor, R., Potchter, O., Shafir, H., and Alpert, P.: An observational study of the summer Mediterranean Sea breeze front penetration into the complex topography of the Jordan Rift Valley, Theor. Appl. Climatol., 127, 275-284, 2017.

Nehorai, R., Lensky, I. M., Lensky, N. G., and Shiff, S.: Remote sensing of the Dead Sea surface temperature, J. Geophys. Res.-Oceans, 114, https://doi.org/10.1029/2008JC005196, c05021, 2009.

Nehorai, R., Lensky, N., Brenner, S., and Lensky, I.: The dynamics of the skin temperature of the Dead Sea, Adv. Meteorol., 2013, 1-9, 2013.

Nied, M.: DESERVE_measurement_data_20160421, available at: https://www.deserve-vi.net/index.php/publications (last access: 7 February 2018), 2016.

Nordbo, A., Launiainen, S., Mammarella, I., Leppäranta, M., Huotari, J., Ojala, A., and Vesala, T.: Long-term energy flux measurements and energy balance over a small boreal lake using eddy covariance technique, J. Geophys. Res.-Atmos, 116, https://doi.org/10.1029/2010JD014542, 2011.

Oroud, I.: Evaluation of saturation vapor pressure over hypersaline water bodies at the southern edge of the Dead Sea, Jordan, Sol. Energy, 53, 497-503, 1994.

Oroud, I.: Evaporation estimates from the Dead Sea and their implications on its water balance, Theor. Appl. Climatol., 106, 523530, https://doi.org/10.1007/s00704-011-0452-6, 2011.

Penman, H. L.: Natural evaporation from open water, bare soil and grass, P. Roy. Soc. Lond. A Mat., 193, 120-145, 1948.

Picard, R. R. and Cook, R. D.: Cross-validation of regression models, J. Am. Stat. Assoc., 79, 575-583, 1984.

Priestley, C. H. B.: On the assessment of surface heat flux and evaporation using large scale parameters, Mon. Weather Rev., 100, 81-92, 1972.

Rimmer, A., Samuels, R., and Lechinsky, Y.: A comprehensive study across methods and time scales to estimate surface fluxes from Lake Kinneret, Israel, J. Hydrol., 379, 181-192, 2009.

Rosenberry, D. O., Winter, T. C., Buso, D. C., and Likens, G. E.: Comparison of 15 evaporation methods applied to a small mountain lake in the northeastern USA, J. Hydrol., 340, 149-166, 2007.

Salameh, E.: Water quality degradation in Jordan (Impacts on Environment, Economy and Future Generations Resources Base), Friedrich Ebert Stiftung, Royal Society for the Conservation of Nature, Amman, 1996.

Salameh, E. and El-Naser, H.: Does the actual drop in Dead Sea level reflect the development of water sources within its drainage basin?, Acta Hydroch. Hydrob., 27, 5-11, 1999.

Salameh, E. and El-Naser, H.: Changes in the Dead Sea Level and their Impacts on the Surrounding Groundwater Bodies, Acta Hydroch. Hydrob., 28, 24-33, https://doi.org/10.1002/(SICI)1521401X(200001)28:1<24::AID-AHEH24>3.0.CO;2-6, 2000. 
Salhotra, A. M., Adams, E. E., and Harleman, D. R. F.: Effect of salinity and ionic composition on evaporation: analysis of Dead Sea evaporation pans, Water Resour. Res., 21, 1336-1344, https://doi.org/10.1029/WR021i009p01336, 1985.

Schotanus, P., Nieuwstadt, F., and De Bruin, H.: Temperature measurement with a sonic anemometer and its application to heat and moisture fluxes, Bound.-Lay. Meteorol., 26, 81-93, https://doi.org/10.1007/BF00164332, 1983.

Shafir, H. and Alpert, P.: Regional and local climatic effects on the Dead-Sea evaporation, Climatic Change, 105, 455-468, https://doi.org/10.1007/s10584-010-9892-8, 2011.

Shilo, E., Ziv, B., Shamir, E., and Rimmer, A.: Evaporation from Lake Kinneret, Israel, during hot summer days, J. Hydrol., 528, 264-275, 2015.

Siebert, C., Rödiger, T., Mallast, U., Gräbe, A., Guttman, J., Laronne, J. B., Storz-Peretz, Y., Greenman, A., Salameh, E., Al-Raggad, M., Vachtman, D., Zvi, A. B., Ionescu, D., Brenner, A., Merz, R., and Geyer, S.: Challenges to estimate surface- and groundwater flow in arid regions: The Dead Sea catchment, Sci. Total Environ., 485-486, 828-841, https://doi.org/10.1016/j.scitotenv.2014.04.010, 2014.

Siebert, C., Rödiger, T., Geyer, S., Laronne, J. B., Hillel, N., Sauter, M., and Mallast, U.: Multidisciplinary investigations of the transboundary Dead Sea basin and its water resources, in: Integrated Water Resources Management: Concept, Research and Implementation, Springer, 107-127, Cham, 2016.

Stanhill, G.: The radiation climate of the dead sea, J. Climatol., 7, 247-265, https://doi.org/10.1002/joc.3370070305, 1987.

Stanhill, G.: Changes in the rate of evaporation from the Dead Sea, Int. J. Climatol., 14, 465-471, https://doi.org/10.1002/joc.3370140409, 1994.

Steiner, L. E.: Introduction to Chemical Thermodynamics, McGraw-Hill Book Co., New York, 510 pp., 1948.

Tanny, J., Cohen, S., Assouline, S., Lange, F., Grava, A., Berger, D., Teltch, B., and Parlange, M.: Evaporation from a small water reservoir: direct measurements and estimates, J. Hydrol., 351, 218-229, https://doi.org/10.1016/j.jhydrol.2007.12.012, 2008.
Van Bavel, C.: Potential evaporation: the combination concept and its experimental verification, Water Resour. Res., 2, 455-467, 1966.

Weast, R. C., Astle, M. J., and Beyer, W. H.: CRC Handbook of Chemistry and Physics, 68th Edition, CRC Press, Boca Raton, USA, 1987.

Webb, E. K., Pearman, G. I., and Leuning, R.: Correction of flux measurements for density effects due to heat and water vapour transfer, Q. J. Roy. Meteor. Soc., 106, 85-100, https://doi.org/10.1002/qj.49710644707, 1980.

Weiss, M., Cohen, A., and Mahrer, Y.: Upper atmosphere measurements and meteorological measurements on the Dead Sea, Tech. rep., Ministry of Energy and Infrastructure, 19 pp., Israel, 1988 (in Hebrew).

Wilczak, J., Oncley, S., and Stage, S.: Sonic anemometer tilt correction algorithms, Bound.-Lay. Meteorol., 99, 127-150, https://doi.org/10.1023/A:1018966204465, 2001.

Wilson, K., Goldstein, A., Falge, E., Aubinet, M., Baldocchi, D., Berbigier, P., Bernhofer, C., Ceulemans, R., Dolman, H., Field, C., Grelle, A., Ibrom, A., Law, B., Kowalski, A., Meyers, T., Moncrieff, J., Monson, R., Oechel, W., Tenhunen, J., Valentini, R., and Verma, S.: Energy balance closure at FLUXNET sites, Agr. Forest Meteorol., 113, 223-243, 2002.

Winter, T., Rosenberry, D., and Sturrock, A.: Evaluation of 11 equations for determining evaporation for a small lake in the north central United States, Water Resour. Res., 31, 983-993, 1995.

Yechieli, Y., Abelson, M., Bein, A., Crouvi, O., and Shtivelman, V.: Sinkhole swarms along the Dead Sea coast: reflection of disturbance of lake and adjacent groundwater systems, Geol. Soc. Am Bull., 118, 1075-1087, 2006. 